\title{
The Influence of Autumnal Eurasian Snow Cover on Climate and Its Link with Arctic Sea Ice Cover $\mathscr{O}$
}

\author{
GUILLAUME GASTINEAU \\ Sorbonne Universités, UPMC/CNRS/IRD/MNHN, LOCEAN/IPSL, Paris, France \\ JAVIER GARCÍA-SERRANO \\ Barcelona Supercomputing Center, Barcelona, Spain \\ Claude Frankignoul \\ Sorbonne Universités, UPMC/CNRS/IRD/MNHN, LOCEAN/IPSL, Paris, France
}

(Manuscript received 22 August 2016, in final form 7 June 2017)

\begin{abstract}
The relationship between Eurasian snow cover extent (SCE) and Northern Hemisphere atmospheric circulation is studied in reanalysis during 1979-2014 and in CMIP5 preindustrial control runs. In observations, dipolar SCE anomalies in November, with negative anomalies over eastern Europe and positive anomalies over eastern Siberia, are followed by a negative phase of the Arctic Oscillation (AO) one and two months later. In models, this effect is largely underestimated, but four models simulate such a relationship. In observations and these models, the SCE influence is primarily due to the eastern Siberian pole, which is itself driven by the Scandinavian pattern (SCA), with a large anticyclonic anomaly over the Urals. The SCA is also responsible for a link between Eurasian SCE anomalies and sea ice concentration (SIC) anomalies in the Barents-Kara Sea.

Increasing SCE over Siberia leads to a local cooling of the lower troposphere and is associated with warm conditions over the eastern Arctic. This is followed by a polar vortex weakening in December and January, which has an AO-like signature. In observations, the association between November SCE and the winter AO is amplified by SIC anomalies in the Barents-Kara Sea, where large diabatic heating of the lower troposphere occurs, but results suggest that the SCE is the main driver of the AO. Conversely, the sea ice anomalies have little influence in most models, which is consistent with the different SCA variability, the colder mean state, and the underestimation of troposphere-stratosphere coupling simulated in these models.
\end{abstract}

\section{Introduction}

The role of Arctic conditions in the midlatitude winter climate is under debate, especially for the North Atlantic sector (Overland et al. 2015). In this region, the atmosphere has a dominant short-time-scale chaotic intrinsic variability and is mainly unpredictable. However, several studies suggest that the variability of Arctic sea ice extent (Yamamoto et al. 2006; Francis et al. 2009; Honda et al.

Supplemental information related to this paper is available at the Journals Online website: https://doi.org/10.1175/ JCLI-D-16-0623.s1.

Corresponding author: Dr. Guillaume Gastineau, guillaume. gastineau@upmc.fr
2009; Wu and Zhang 2010; Frankignoul et al. 2014; García-Serrano et al. 2015; Koenigk et al. 2016; King et al. 2016) and Eurasian snow cover extent (SCE, e.g., Cohen and Entekhabi 1999; Cohen et al. 2007; Cohen and Jones 2011) have some influence on the atmosphere during winter. Such influence may account for an improvement in skill of long-range prediction due to continental snow (Jeong et al. 2013; Orsolini et al. 2013) and sea ice (Scaife et al. 2014) initialization and improved physics (Riddle et al. 2013) in current forecast systems.

Continental snow cover affects the atmosphere via changes in surface albedo (Cohen 1994). A larger snow cover increases the surface albedo and reflects shortwave radiation away from the surface (Gong et al. 2004; Jeong et al. 2013). A snowpack also insulates the atmosphere from the soil surface. In winter at high latitude, these two 
effects explain the fact that snow enhances the diabatic cooling at the surface and in the atmospheric boundary layer (Fletcher et al. 2007; Dutra et al. 2011), which locally increases the sea level pressure (SLP). A larger SCE over Eurasia has been reported to intensify and expand the Siberian high (Jeong et al. 2011; Orsolini et al. 2013). This modifies the land-sea contrast and the stationary wave pattern and may lead to enhanced upward planetary wave propagation, thus weakening and warming the polar vortex in the stratosphere (Saito et al. 2001; Cohen et al. 2007; Orsolini et al. 2016). A weak polar vortex can persist for several weeks and influence the underlying troposphere by downward propagation of circulation anomalies. The influence of the Eurasian snow cover has received most attention in autumn, as it shows a statistically significant relation with the following winter Arctic Oscillation (AO) and North Atlantic Oscillation (NAO), from December to March (Cohen et al. 2007; Déry and Brown 2007; Allen and Zender 2010; Cohen et al. 2012).

Sea ice concentration (SIC) changes may also influence the atmosphere. The most reported influence concerns SIC in the Barents-Kara Sea, where SIC in autumn has a statistically significant influence on the following winter NAO (Petoukhov and Semenov 2010; Kim et al. 2014; García-Serrano et al. 2015; King et al. 2016). Sea ice insulates the ocean from the atmosphere, so that a sea ice loss increases the heat flux from the ocean to the atmosphere. The resulting diabatic heating is large, but localized near the sea ice edge (e.g., Magnusdottir et al. 2004; Deser et al. 2004, 2007). This leads to changes in the tropospheric eddies and the planetary wave pattern, which may alter the polar vortex (e.g., Nakamura et al. 2015, 2016). The modified polar vortex may then influence the troposphere by downward propagation in the following weeks or months, with important impact during periods of polar vortex breakdown, such as in February (Jaiser et al. 2016).

The influence of SIC thus shares a large similarity with that of the Eurasia SCE during fall (October and November), as both may involve a stratospheric pathway. Furthermore, continental SCE and Arctic SIC are linked, as a reduced Arctic sea ice extent leads to a moistening of the atmospheric boundary layer, which increases the moisture flux into eastern Siberia, increasing snowfall, as suggested by Cohen et al. (2014a) and found by Wegmann et al. (2015) using a Lagrangian analysis. The sea ice and snow cover are also connected by the influence of Ural blocking, which has been reported to cause warm Arctic-cold Eurasia anomalies in winter (Luo et al. 2016). The two surface influences are, therefore, connected, and their interaction might amplify the atmospheric response found by separately considering snow cover and sea ice (Cohen et al. 2014a).
However, only a few studies have investigated the links between the SCE and sea ice. The relative effect on the atmosphere of the Arctic sea ice and Eurasian snow cover is largely unknown. In addition, the influence of tropical SST variability needs to be clarified, as the tropical teleconnections may both influence the snow cover over Eurasia and modify the atmospheric circulation (Fasullo 2004), leading to a possible confusion between cause and effect.

As the observational record is mostly limited to the recent decades, climate models can be used to investigate the impact of SIC and SCE variability with a much larger sampling, even if the stratospheric polar vortex is too stable in models, which may inhibit the troposphere-stratosphere coupling (Furtado et al. 2015). The aim of this study is to investigate the influence of autumnal Eurasian snow cover variability in observations and climate models, and the links with that of the sea ice cover. We find that snow cover anomalies in November have a dominant influence on the atmospheric circulation in observations and several models. The SCE anomalies are found to be associated with SIC anomalies over the Barents-Kara Sea, as both are modulated by the Scandinavian pattern, which is the dominant mode of atmospheric variability in November.

The next section describes the methodology. The analysis of the snow cover and its links with the atmosphere is discussed in section 3 . The processes linking the snow cover to the atmosphere are investigated in section 4 . Finally, the last section contains the discussion and conclusions.

\section{Data and methods}

\section{a. Observations}

Monthly sea ice cover is downloaded from the National Snow and Ice Data Center (Comiso 2012). Weekly Northern Hemisphere continental snow cover is retrieved from the NOAA-Rutgers University Global Snow Laboratory and aggregated into monthly data. Both products are based on passive microwave measurements (SSM/I) and extend from 1979 to 2014. The sea level pressure, geopotential height, air temperature, and heat flux (accumulated from 24-h forecasts) are from the ERA-Interim reanalysis (Dee et al. 2011).

A quadratic trend is removed from all variable before the analysis to remove the effect of the global warming. This also removes the multidecadal variability and lower frequencies, and the large Arctic sea ice decrease from 2005 onward (e.g., Close et al. 2015).

\section{b. Models}

Monthly SLP, snow cover, geopotential, SIC, SST, and heat fluxes anomalies are downloaded from the CMIP5 
TABLE 1. CMIP5 models and control simulations used. (Expansions of acronyms are available online at http://www.ametsoc.org/ PubsAcronymList.)

\begin{tabular}{|c|c|c|c|c|}
\hline & Group & Model & AGCM resolution & Length $(\mathrm{yr})$ \\
\hline 1 & $\mathrm{CCCma}$ & CanESM2 & $2.8^{\circ} \times 2.8^{\circ} \mathrm{L} 35$ & 995 \\
\hline 2 & CNRM-CERFACS & CNRM-CM5 & $1.4^{\circ} \times 1.4^{\circ} \mathrm{L} 31$ & 850 \\
\hline 3 & CSIRO-QCCCE & CSIRO-Mk3.6.0 & $1.9^{\circ} \times 1.9^{\circ} \mathrm{L} 18$ & 500 \\
\hline 4 & LASG-CESS & FGOALS-g2 & $2.8^{\circ} \times 2.8^{\circ} \mathrm{L} 26$ & 700 \\
\hline 5 & MIROC & MIROC-ESM & $1.4^{\circ} \times 1.4^{\circ} \mathrm{L} 40$ & 630 \\
\hline 6 & MPI-M & MPI-ESM-LR & $1.9^{\circ} \times 1.9^{\circ} \mathrm{L} 47$ & 1000 \\
\hline 7 & MRI & MRI-CGCM3 & $1.1^{\circ} \times 1.1^{\circ} \mathrm{L} 48$ & 500 \\
\hline 8 & NASA-GISS & GISS-E2-R & $2.5^{\circ} \times 2^{\circ} \mathrm{L} 40$ & 550 \\
\hline 9 & NCAR & CCSM4 & $1.25^{\circ} \times 0.9^{\circ} \mathrm{L} 26$ & 600 \\
\hline 10 & $\mathrm{NCC}$ & NorESM1-ME & $2.5^{\circ} \times 1.9^{\circ} \mathrm{L} 26$ & 250 \\
\hline 11 & NSF-DOE-NCAR & CESM1-BGC & $1.25^{\circ} \times 0.9^{\circ} \mathrm{L} 26$ & 500 \\
\hline 12 & IPSL & IPSL-CM5A-LR & $1.9^{\circ} \times 3.75^{\circ} \mathrm{L} 39$ & 1000 \\
\hline
\end{tabular}

archive for 12 coupled ocean-atmosphere models (Table 1) using the preindustrial multicentennial control simulations with constant external forcing. All model fields are interpolated onto a common $2.5^{\circ} \times 2.5^{\circ}$ horizontal grid. A quadratic trend was removed from all outputs to remove the possible influence of model drift.

\section{c. Maximum covariance analysis}

Maximum covariance analysis (MCA) is used to estimate the main modes of area-weighted covariability between the atmosphere and the underlying snow cover. We use snow cover anomalies over northern Eurasia $\left(40^{\circ}-65^{\circ} \mathrm{N}, 0^{\circ}-180^{\circ} \mathrm{E}\right)$. The SLP anomalies in the Northern Hemisphere $\left(20^{\circ}-90^{\circ} \mathrm{N}\right)$ are chosen to represent the tropospheric circulation. The MCA decomposes the covariance matrix of the two fields using singular value decomposition (Bretherton et al. 1992). Each mode of covariability is characterized by two time series and associated spatial patterns. Here, the MCA time series are standardized (divided by their standard deviation). The spatial patterns are illustrated by the homogeneous covariance map for the field that leads (regression on the same field time series) and the heterogeneous covariance map for the field that lags (regression on the MCA time series of the other field), which preserves orthogonality (Czaja and Frankignoul 2002). The MCA modes are characterized by their normalized squared covariance (NSC; i.e., the squared singular value divided by the variance of both fields), the correlation $(R)$ between the MCA time series, and the squared covariance fraction (SCF; i.e., the ratio of covariance explained). To evaluate the robustness of the MCA modes, we repeated the MCAs using 100 random permutations of 3-yr blocks for the SLP field. The number of NSC and $R$ that exceed the observed values gives the levels of significance for NSC and $R$.
The modes of covariability between the snow cover and the atmosphere are expected to reflect the influence of atmospheric perturbations on the SCE when the two fields are in phase or, because of snow cover persistence, when the atmosphere leads. When the snow cover leads the atmosphere by one month or more, a significant MCA mode could indicate an influence of the snow cover (or concomitant boundary forcing) on the atmosphere, as the extratropical atmosphere has an intrinsic persistence of at most 10 days (Vautard 1990). However, El Niño-Southern Oscillation (ENSO) has persistent remote teleconnections that may give rise to persistent MCA modes not solely linked to local boundary forcing. Hence, we (largely) remove these teleconnections from both snow and atmospheric data by multivariate regression when (and only when) the snow cover field leads the atmosphere, assuming that they lag the tropical Pacific SST by two months in the atmosphere, while they vary with lag for the snow in order to get unbiased estimates (see Frankignoul et al. 2011). The tropical SST variability is represented by the first three empirical orthogonal functions (EOFs) of the monthly tropical Indo-Pacific SST. The regressions are performed separately for each season, to account for the seasonal changes of the ENSO teleconnection, and separately for positive and negative values of the principal components (PCs) to account for the asymmetry (see the online supplemental material for details). We verified that similar MCA results are obtained by assuming a onemonth lag for the ENSO teleconnections, or even without removing the ENSO signal (see supplemental Table S1).

\section{d. Rotated empirical orthogonal function}

The main patterns of Northern Hemisphere $\left(20^{\circ}-90^{\circ} \mathrm{N}\right)$ SLP variability are given by rotated empirical orthogonal 


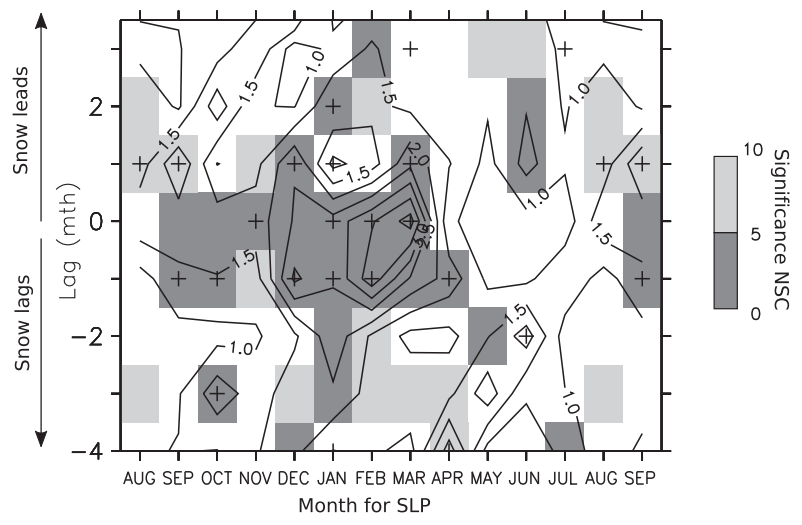

FIG. 1. Normalized squared covariance (NSC; contours, in \%) for the first MCA mode between observed SLP and Eurasian snow cover, for each month in the atmosphere. The lag is positive when the snow cover leads SLP. The gray shading provides the level of statistical significance for NSC. The plus symbols indicate the atmospheric month and time lag where the level of significance for the correlation $(R)$ is below $5 \%$

function (REOF) analysis, using the first 15 EOFs in the rotation, which accounts for $95 \%$ of the variance. To preserve orthogonality of the PCs, we scaled the EOFs by the square root of its eigenvalue before performing the varimax rotation (Kaiser 1958). The rotated PCs are standardized, and the REOF patterns are given by regression on these time series.

\section{e. Regression analysis}

We used both univariate and multivariate least squares regression. We remove the tropical teleconnections from all data before the regression analysis, following the same methodology as the MCA (see section 2c). The level of statistical significance is tested with 100 permutations of the atmospheric fields in 3-yr blocks to take serial autocorrelation into account. The number regression slope that exceeds the observed value in the permuted time series provides the $p$ value.

\section{The links between Eurasian snow cover and the atmosphere}

\section{a. Detection of the snow cover influence}

The normalized squared covariance of the first MCA mode provides an estimate of the dominant covariability between the SCE and SLP anomalies. It is shown as a function of lag and season for the observations in Fig. 1. The largest NSC values are mostly obtained when the atmosphere is in phase with the SCE or leads it by one month (negative lag), reflecting that the atmosphere controls the formation of snow cover anomalies. The largest covariability occurs for SLP in March at lag 0 and for SLP in February when it leads by one month. This is consistent with the occurrence of the largest interannual snow anomalies in March and the largest atmospheric variability in February.

At positive lag, the snow cover leads the atmosphere, which may reflect the SCE forcing of atmospheric anomalies. The most significant links are found between November snow cover and SLP in December (lag 1) and January (lag 2), as well as between February snow cover and SLP in March (lag 1), as the NSC and $R$ are both significant at the $5 \%$ level (Fig. 1). The covariability is weaker when October SCE leads the atmosphere, whether by 1,2 , or 3 months ( $p$ values are $10 \%, 28 \%$, and $40 \%$ for NSC and $13 \%, 38 \%$, and $20 \%$ for $R$, respectively). Our results thus contrast with the commonly argued impact of October Eurasian snow cover on winter SLP (Saito and Cohen 2003), as further discussed in the appendix. A significant covariance ( $p$ value $<10 \%$ ) is also found for SLP in August and September, when the SCE leads by one month.

The influence of November SCE on the atmosphere in December and January is the main focus of this paper, and it is discussed below. The late winter snow influence found in March has been reported in several studies (Barnett et al. 1989; Saito and Cohen 2003; Zhang et al. 2004; Peings and Douville 2010; Peings et al. 2011); it is not investigated here, as the processes are different from the fall influence studied here. Similarly, the covariability in late summer is not discussed here; it shows a reduction of snow cover in southwestern Norway preceding anticyclonic conditions over the North Atlantic (not shown) and might be due to concomitant North Atlantic SST forcing (Gastineau and Frankignoul 2015).

The same analysis has been performed with the CMIP5 models, and a significant covariability between SCE and SLP anomalies is found in several cases. The results are summarized in Fig. 2, which shows the level of statistical significance of the NSC and $R$ for the first MCA mode (left panel). The similarity with the observational data is given by the spatial pattern correlation of the homogeneous SCE and heterogeneous SLP covariance maps between each model and the observation (right panel). When using November SCE anomalies and December SLP (black symbols in Fig. 2), there are 4 models out of 12 (CanESM2, MPI-ESM-LR, GISSE-R, and CESM1) suggesting an impact of the November SCE anomalies that is reasonably similar to that observed (spatial correlation between 0.2 and $0.9)$. These four models show a first MCA mode that is $10 \%$ significant for NSC and $R$, except for MPI-ESMLR, which is only $12 \%$ significant for $R$. Among these four models, only CESM1 is a low-top model, while the 

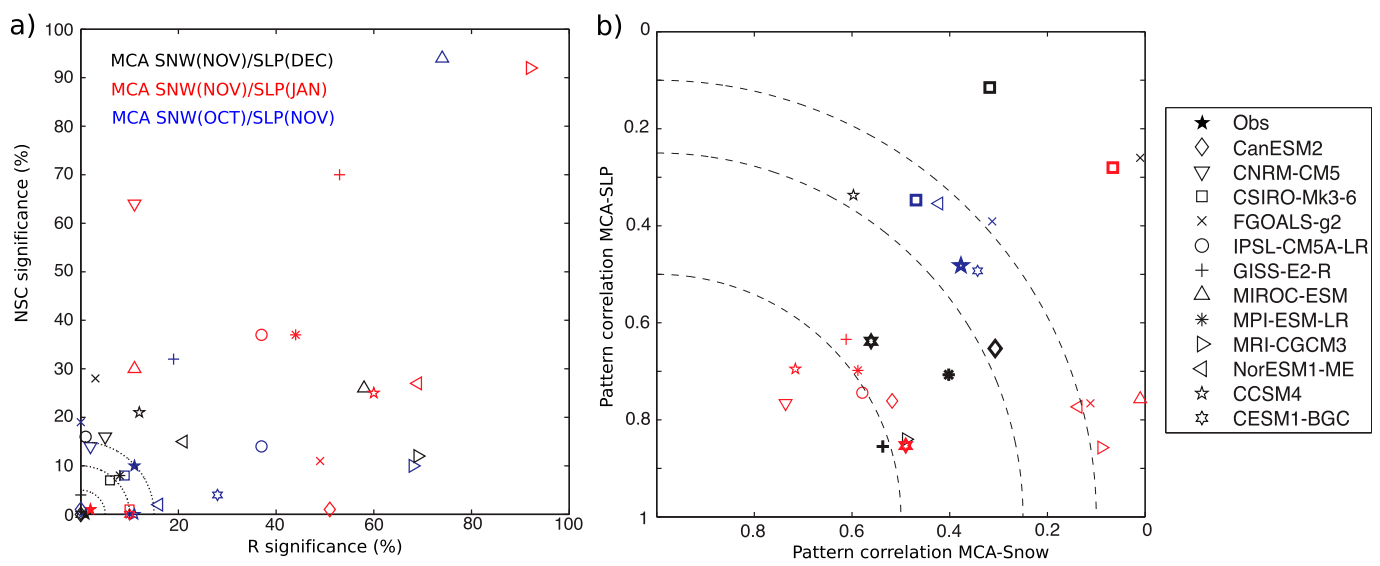

FIG. 2. (a) Scatterplot of the confidence level (in \%) of the normalized squared covariance vs that of the correlation, $R$, for the first MCA mode between SLP and Eurasian snow cover. (b) Scatterplot of the spatial correlation between the SLP covariance map found in models and that of ERA-Interim, versus the spatial correlation between the snow cover covariance map found in models and that of ERA-Interim. The black indicates the results for SLP in December and SCE in November (1-month lag). The blue indicates the results for SLP in November and SCE in October (1month lag). The red indicates the results for the SLP in January and SCE in November (2-month lag). In (b), the bold symbols indicate levels of significance lower than $15 \%$ for both NSC and $R$.

others are high-top models with lid height above $45 \mathrm{~km}$ (Seviour et al. 2016).

The SCE influence seems to be less persistent in models, as the first MCA mode with November SCE is only significant at lag 2 (SLP in January) in CESM1 (red symbols in Fig. 2). When using October SCE and November SLP (blue symbols in Fig. 2), there are only two models out of 12 suggesting an impact of the October snow cover anomalies (CSIRO-Mk3.6 and CCSM4). When using October SCE and December (January) SLP, only one model, FGOALS-g2 (IPSL-CM5A-LR), provides a potential impact. We conclude that, consistent with observations, more CMIP5 models suggest an impact of November SCE than October SCE. Next, we will discuss the spatial patterns corresponding to these modes of covariability.

\section{b. Spatial pattern of the November snow cover influence}

The covariance maps for November SCE and December SLP are shown in Fig. 3. In observations, the first MCA mode shows dipolar snow cover anomalies (Fig. 3a, colors), with a pole over eastern Europe and an opposite polarity over southeastern Siberia, northern Mongolia, and northern China. Both poles are located at the margin of the snow-covered surface in November (see Fig. S1). This SCE dipole precedes SLP anomalies (black contours) broadly projecting on a negative phase of the AO, with a large signature over the North Atlantic. The covariance maps at lag 2 (Fig. 3b; November SCE/January SLP) are almost identical, but the SLP anomalies are weaker, especially over western Europe. Note that the covariance maps at lag 3 (November SCE/ February SLP) are also similar, although the significance levels for NSC and $R$ are $1 \%$ and $27 \%$, respectively.

The MCA patterns in the four CMIP5 models (CanESM2, MPI-ESM-LR, GISS-E-R, and CESM1) identified previously are broadly similar to the observed ones (Figs. 3c-f), with a positive snow cover anomaly in southern Siberia and a negative one over eastern Europe preceding a negative AO-like pattern by one month. However, the amplitudes are smaller than in observations (note the different color and contour interval in Fig. 3). Furthermore, the snow cover anomalies are slightly shifted, as the November SCE climatology shows less snow over Eurasia, especially over Europe (Fig. S1). In the following, we only consider this subset of four models, as illustrated by the averaged covariance map (Fig. 3g).

To take into account the different sampling in models ( $\geq 500 \mathrm{yr}$ ) and observations ( $36 \mathrm{yr}$ ), we performed similar MCA analysis on separate 36-yr segments from each of the four model simulations. These 36-yr segments are selected using a shift of 6 years between two consecutive ones, so that for instance a 1000-yr run results in 16036 -yr segments. The mean NSC and $R$ values for the first MCA mode in these segments are larger than the ones computed from the entire run (see Fig. 3h and values at the top of Figs. 3c-f) but still smaller than in observations, with the $95 \%$ percentile of their distributions lower than the observed value. Therefore, it is very likely that the models do underestimate the snow influence. 

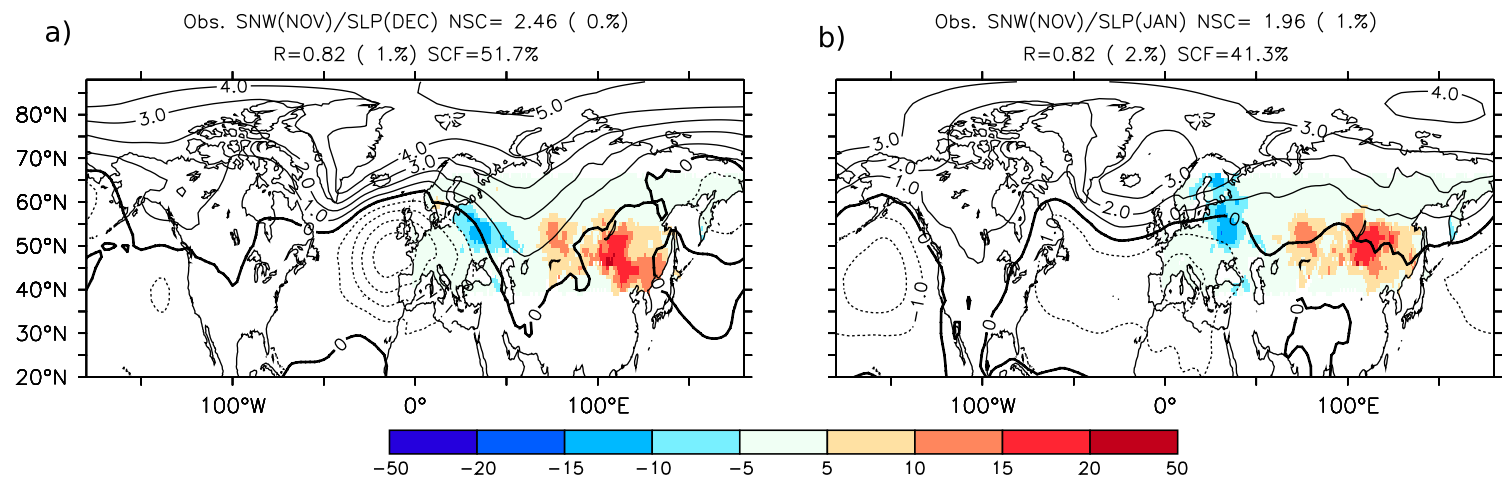

c) CanESM2 SNw(NOV)/SLP(DEC) NSC $=0.09(0 . \%)$

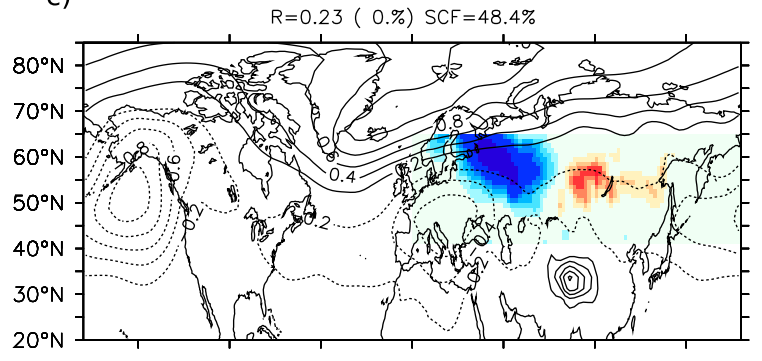

e) $\quad$ GISS-E2-R SNW(NOV)/SLP(DEC) NSC $=0.11$ ( 4.\%) $\mathrm{R}=0.27(0 . \%) \mathrm{SCF}=41.7 \%$

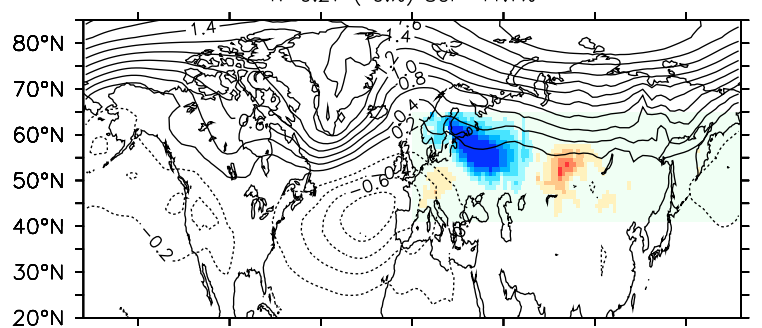

d)

d) $\quad \mathrm{MPI}-E S M-L R$ SNW(NOV) $/ \mathrm{SLP}(\mathrm{DEC}) \mathrm{NSC}=0.05(8 . \%)$

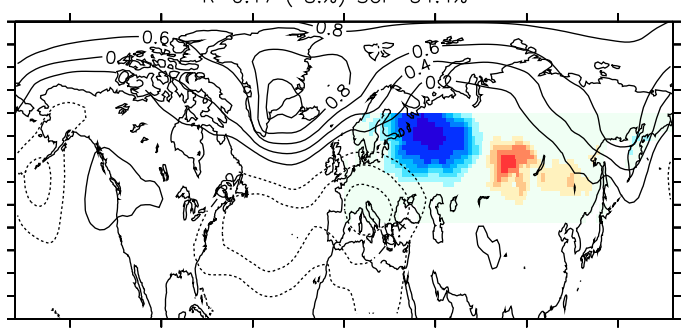

f) $\quad C E S M 1-B G C S N W(N O V) / S L P(D E C) N S C=0.17(0 . \%)$

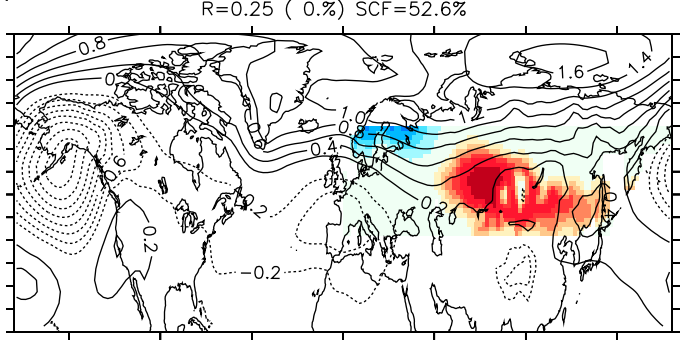

g) SNW(NOV)/SLP(DEC) MEAN

h)
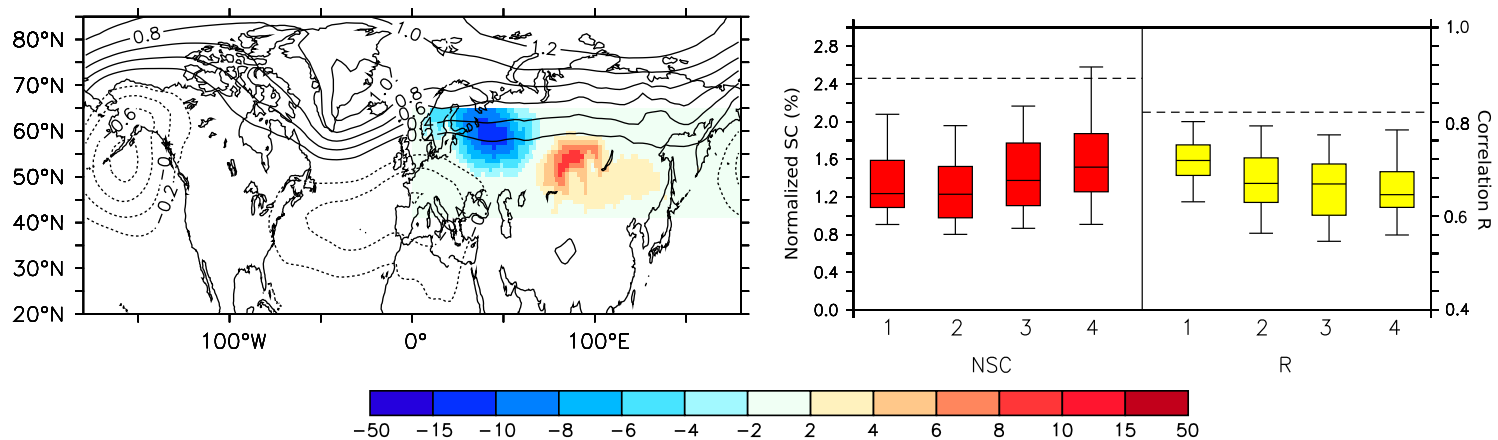

FIG. 3. (a) Homogeneous snow cover fraction (in \%) and heterogeneous SLP (in hPa) covariance maps for the first MCA mode, for December SLP and November snow cover, when the snow cover leads by one month the atmosphere, in ERA-Interim. (b) As in (a), but using January SLP with a 2-month lag. (c)-(g) As in (a), but for CanESM2, MPI-ESM, GISS-E2-R, CESM1-BGC, and the mean of the four models, respectively. Note that the color scale is different for observation and models. (h) Box plots of the NSC and R statistics from the MCA using 36-yr periods extracted from the control runs of each models (1: CanESM2, 2:MPI-ESM, 3: GISS-E2-R, and 4: CESM1-BGC); error bars show the 5\% and $95 \%$ percentiles. The dashed horizontal lines show the NSC and $R$ values in observations. 
a)

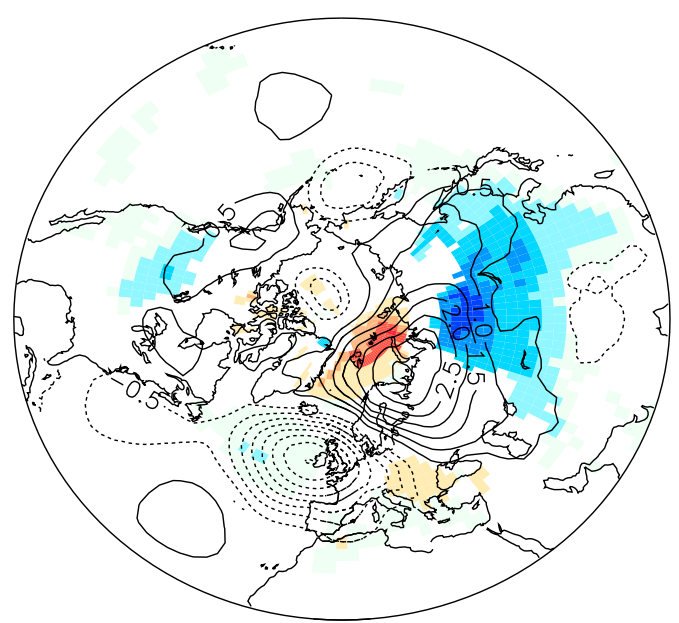

b)

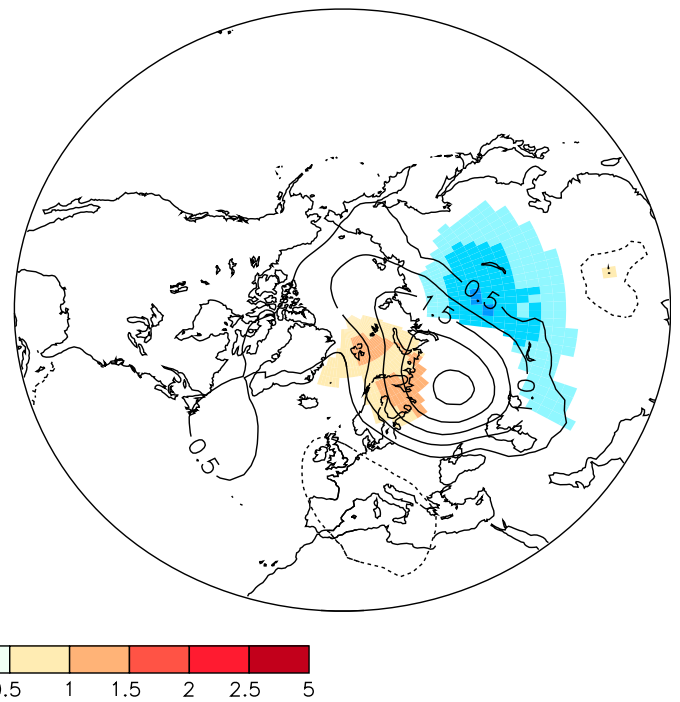

FIG. 4. Regression of SLP (contours, in hPa) and 2-m air temperature, (color, in $\mathrm{K}$ ) on the MCA-snow index, in November, for (a) ERA-Interim and (b) the subset of four models. In (a), colors are masked if the level of significance is above $10 \%$ for observation. In (b), colors indicate anomalies of the same sign among the four models.

\section{c. Origin of the snow cover dipolar variability in November}

To determine the origin of the dipolar snow cover anomalies, November SLP and 2-m air temperature anomalies are regressed onto the (standardized) MCA time series of November SCE, referred to as "MCAsnow" (Fig. 4). For the CMIP5 models, we only consider the four models (CanESM2, MPI-ESM, GISS-E2-R, and CESM-BGC) that are consistent with observations and show the multimodel average of the regression patterns, while the number of models with a regression of the same sign documents their robustness and provides a measure of intermodel spread.

The SLP anomalies associated with the snow dipole in both observations (Fig. 4a) and models (Fig. 4b) are characterized by a large anticyclonic anomaly over the Urals and a depression over Europe. The SLP pattern shares some similarity with the Eurasian pattern type 1 (Barnston and Livezey 1987), the Scandinavian pattern (Bueh and Nakamura 2007), the Russian pattern (Smoliak and Wallace 2015), or the anomalies in Ural blocking conditions (Luo et al. 2016). A similar pattern was also reported to result from the October SCE response (Cohen et al. 2014b). We will refer to this atmospheric pattern as the Scandinavian pattern (SCA) in the following. Figure 4 illustrates that warm (cold) air temperature anomalies are associated with negative (positive) SCE anomalies, consistent with the warm (cold) advection by the anomalous atmospheric circulation, as in the Greenland, Barents, and Kara Seas, which are affected by warm advection from the Norwegian Sea.

In observations, a dipolar SCE pattern similar to that in Fig. 3a and an SCA-like SLP pattern is also obtained as first MCA mode of simultaneous SLP and SCE anomalies in November, with $42.1 \%$ of squared covariance fraction (SCF), as shown in (Fig. 5a), while an AO influence onto the snow cover is only obtained as mode $3(\mathrm{SCF}=11.6 \%)$. This is consistent with the first REOF of November SLP, which corresponds to the SCA (Fig. 6a). In December, however, the simultaneous covariability between SLP and SCE is dominated by the $\mathrm{AO}(\mathrm{SCF}=55.1 \%$; Fig. $5 \mathrm{~b}$ ), which decreases the advection from the relatively warm ocean toward the cooler Eurasian continent. It also shifts southward the precipitation associated with the Atlantic storm track (Hurrell 1995), which increases the SCE over Europe. We also see negative SCE anomalies east of the Caspian Sea associated with warm advection from the Mediterranean region.

On the other hand, the MCA suggests that, in most of the four models, the AO already has the largest impact on snow cover in November (Fig. 5c), with a much larger impact downstream of Europe, as shown by the positive anomalies over eastern Siberia. Only CESM1 simulates the SCA pattern and its dipolar snow cover signature as first MCA mode (not shown). In fact, the first REOF of November SLP is also AO-like in all models (Fig. 6b). To establish its robustness, we have used as above distinct 36-yr chunks from each control simulation to 
a)

Obs 79-14

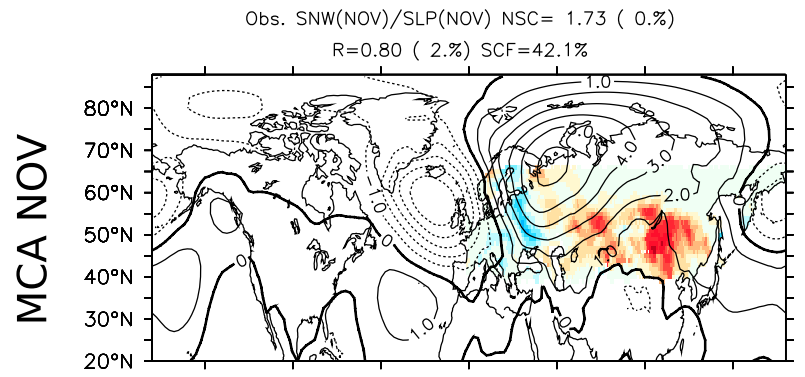

b) Obs. $\mathrm{SNW}(\mathrm{DEC}) / \mathrm{SLP}(\mathrm{DEC}) \mathrm{NSC}=2.56(0 . \%)$
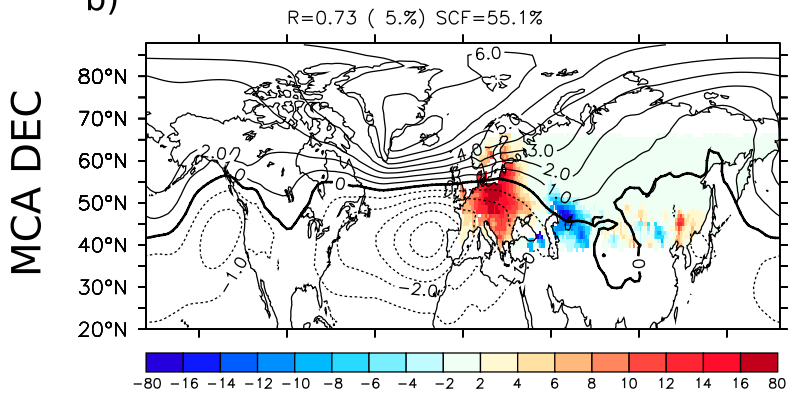

c)

\section{Models}

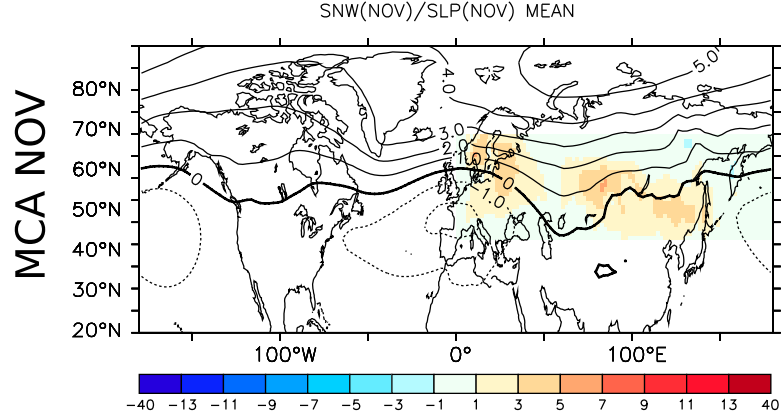

FIG. 5. Homogeneous SLP (in $\mathrm{hPa}$ ) and heterogeneous snow cover (in \%) covariance maps for the first MCA mode, when the SLP and snow cover are simultaneous (no lag), for (a) November fields in ERA-Interim, (b) December fields in ERA-Interim, and (c) November fields in the mean of the four models.

reproduce the observed sampling. The SCA and AO are identified using the largest spatial pattern correlation with the observed SCA (November REOF1) and AO (November REOF3), respectively. The AO variance fraction is systematically larger than observed (Fig. 6c, yellow), while the SCA one is smaller (Fig. 6c, red). This is consistent with the larger role of the SCA in the observation, when compared to model simulations, and it can be explained by either natural atmospheric variability or model biases. Indeed, CMIP5 models use relatively coarse horizontal resolutions and are known to underestimate winter blocking episodes (Dawson et al. 2012), leading to an overestimation of the NAO regimes (Cattiaux et al. 2013). a)
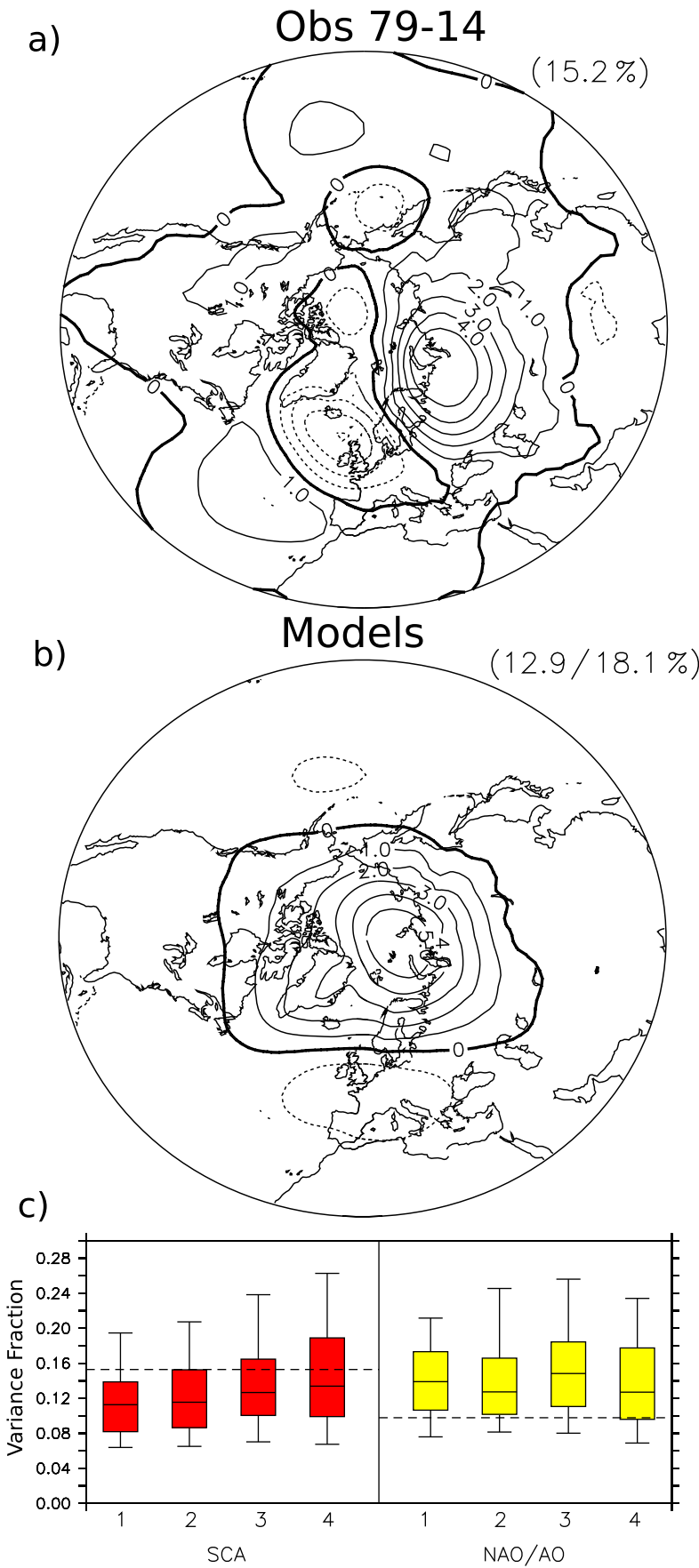

FIG. 6. (a) REOF1 of November SLP (in hPa) in ERA-Interim. (b) As in (a), but for the model mean REOF1 using the four models. In (a), the variance fraction is given in parentheses. In (b), the minimum and maximum variance fraction among the four models is indicated in parentheses. (c) Box plots of the November variance (in \%) explained by the SCA and the NAO/AO in 36-yr chunks from the control runs of each models (1: CanESM2, 2: MPI-ESM, 3: GISS-E2-R, and 4: CESM1-BGC); the error bars give the $5 \%$ and $95 \%$ percentiles, and the dashed horizontal lines the AO and SCA variance fraction in observations. 
a)

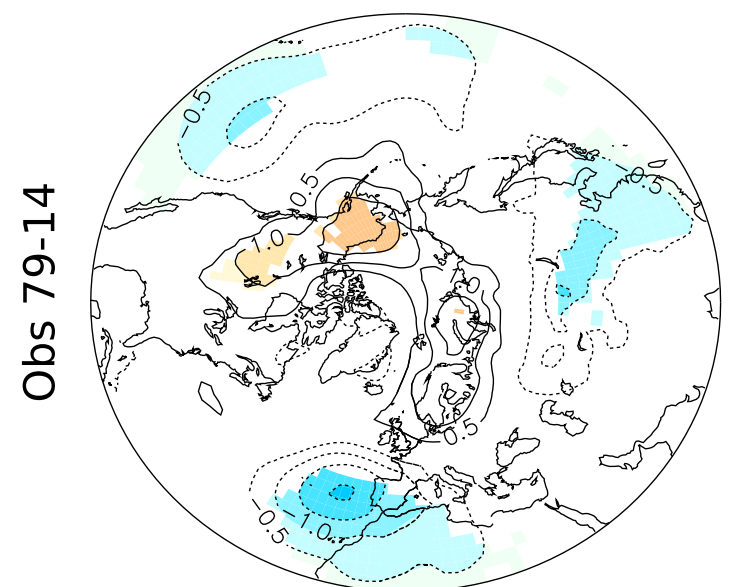

b) Snow-SIB

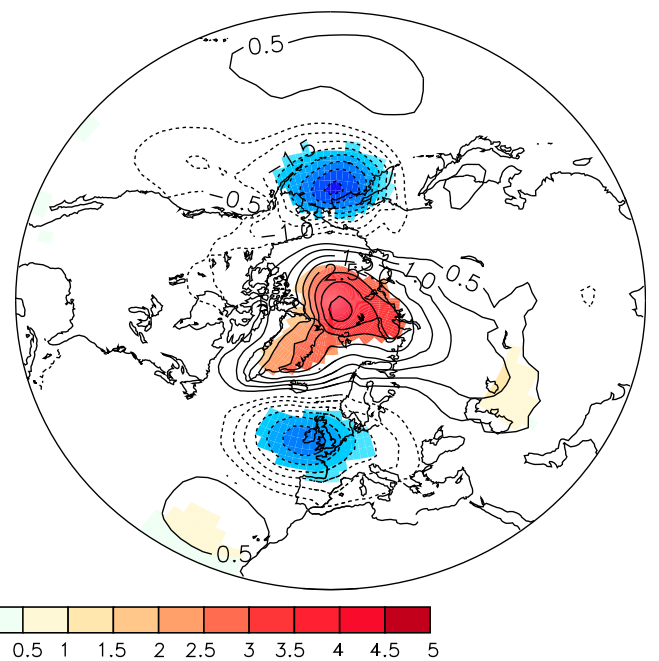

c)

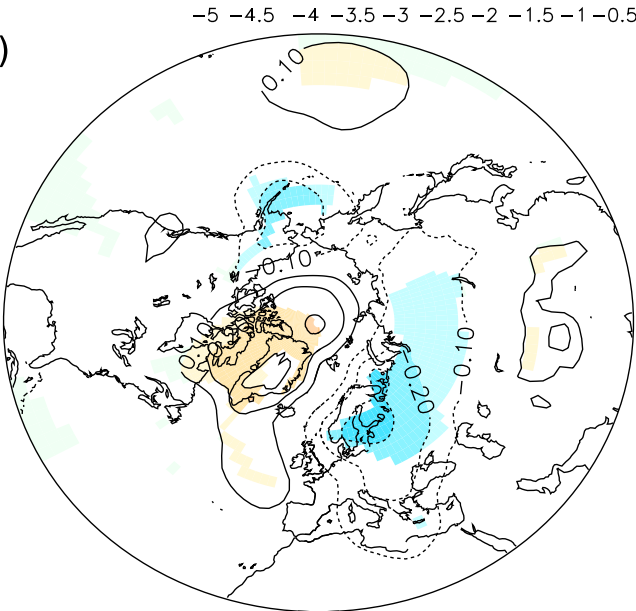

d)

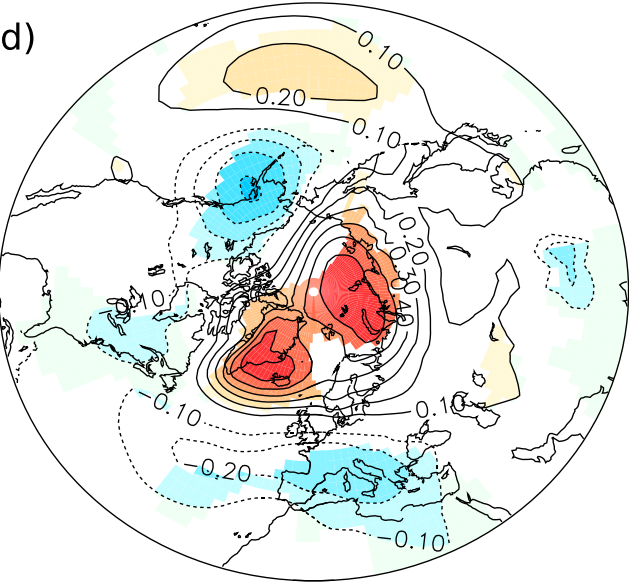

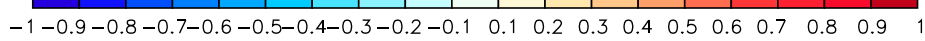

FIG. 7. Regression of the December SLP in hPa onto (left) European and (right) Siberian snow anomalies, given by multivariate regression, for (a),(b) ERA-Interim and (c),(d) the subset of four models. In (a) and (b), colors are masked if the level of statistical significance is above $10 \%$. In (c) and (d), colors indicate anomalies of the same sign among the four models.

\section{Processes of the November snow cover influence}

\section{a. Role of Siberian snow cover}

The relative importance of the two poles of the November SCE dipole can be analyzed using two indices: the mean SCE anomalies over eastern Europe $\left(48^{\circ}-60^{\circ} \mathrm{N}\right.$, $\left.20^{\circ}-58^{\circ} \mathrm{E}\right)$ and over eastern Siberia $\left(43^{\circ}-56^{\circ} \mathrm{N}, 70^{\circ}-140^{\circ} \mathrm{E}\right)$. A bivariate regression of SLP anomalies in December on these two indices shows significant SLP anomalies in the observations (Figs. 7a,b), with negative SLP anomalies off western Europe and positive anomalies over the polar cap. However, the eastern Siberia pole has the largest and most significant influence on SLP, and its impact is more AO-like. In the four models
(Figs. 7c,d), Siberian SCE anomalies also have a larger AO-like influence on SLP, while European SCE is linked to a weak SLP dipole between Greenland and Scandinavia. Therefore, the most robust signal seems to be linked to the Siberian SCE influence, which is consistent with the reported influence of October snow cover (Saito and Cohen 2003).

\section{b. Associated surface changes}

The influence of surface conditions is evaluated using SCE and SIC regressions onto MCA-snow in Fig. 8. The November SCE anomalies (Figs. 8c,d) are preceded in October (Figs. 8a,b) and followed in December (Figs. 8e, f) by similar, but smaller, anomalies over 
a)

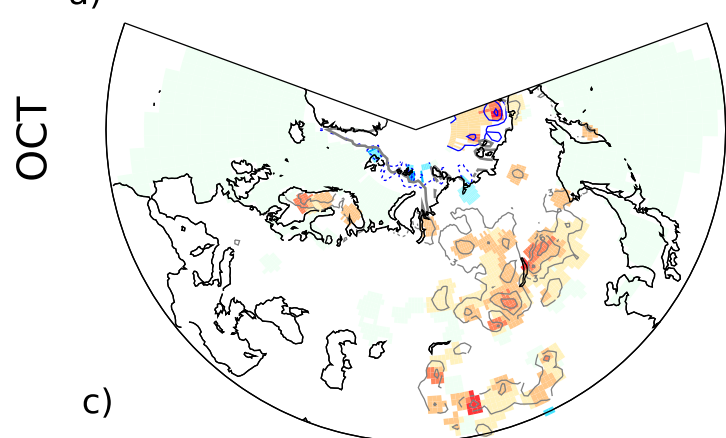

b)

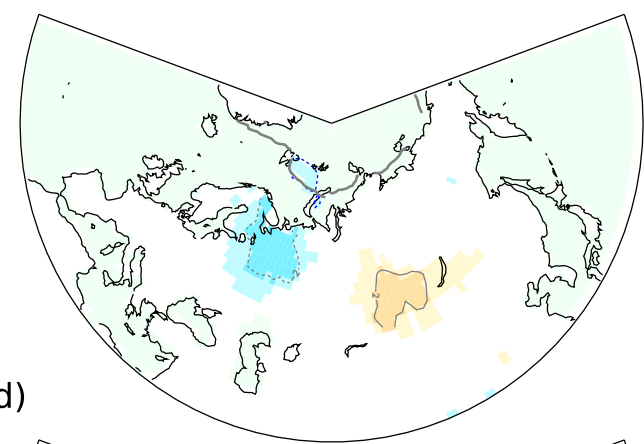

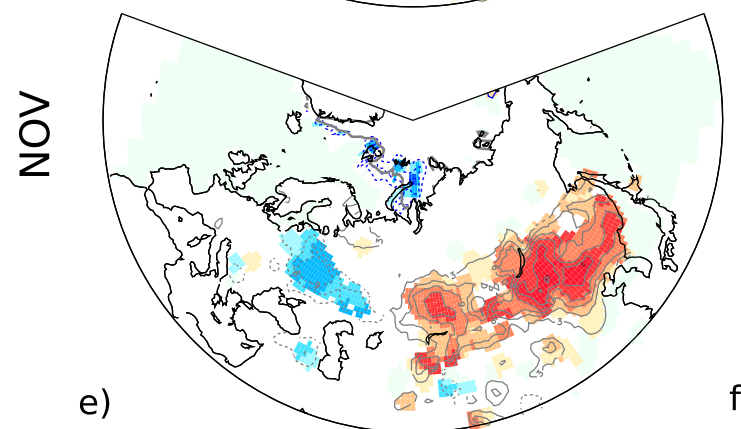
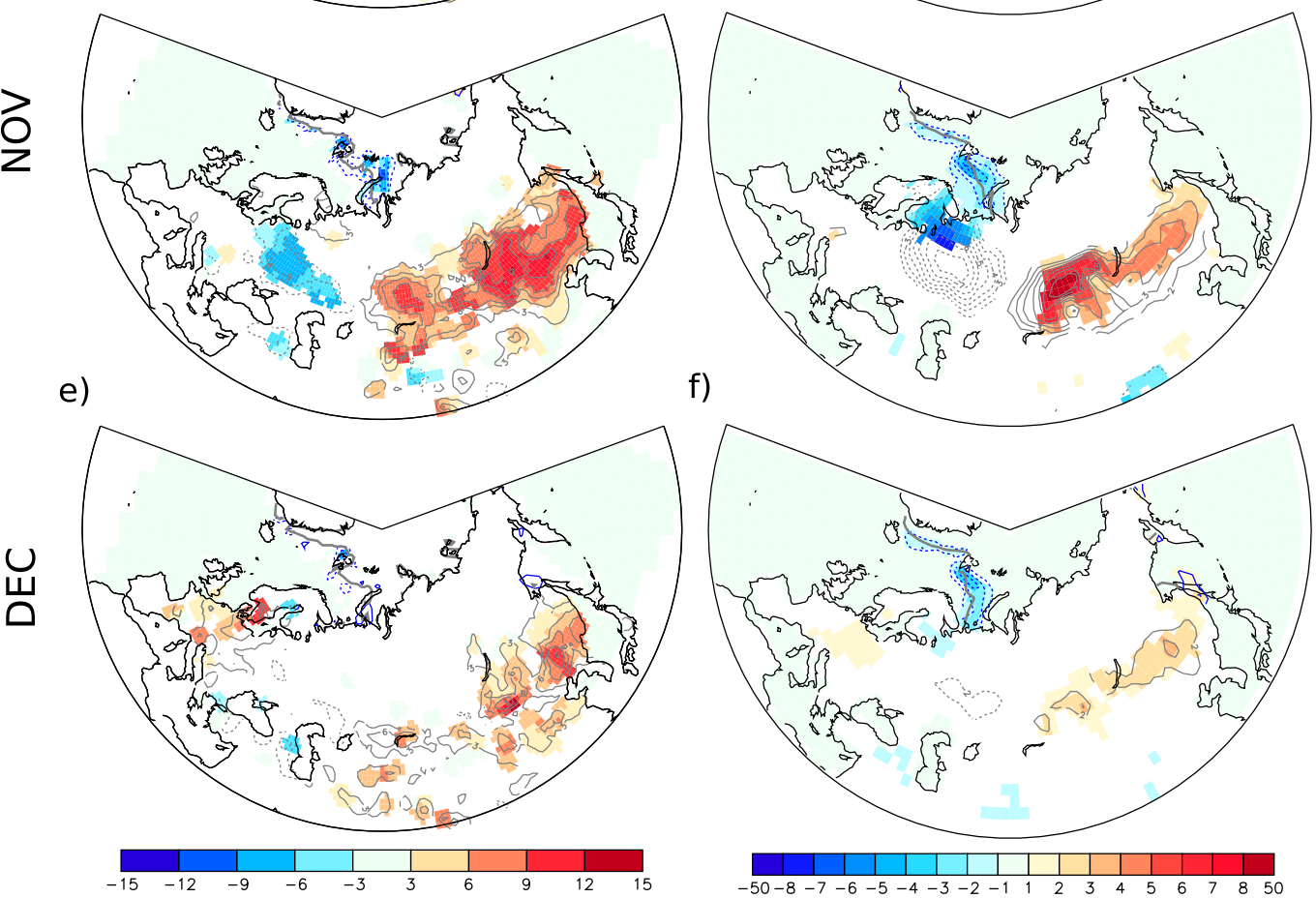

FIG. 8. Regression of the snow cover fraction (gray contours and color shading over continent; in \%) and sea ice concentration (blue contours and color shading over the ocean; in \%), onto the November MCA-snow index, for (a) ERA-Interim in October and (b) the four models in October. (c),(d) As in (a),(b), but for November; (e),(f) as in (a),(b), but for December. The sea ice concentration contour interval is $5 \%$ in observations and $1 \%$ for models; the zero contour is removed. The thick gray contour provides the $50 \%$ contour for climatological SIC.

eastern Siberia, which is consistent with the snow cover persistence over that region (Déry and Brown 2007), and reflected in the large correlation (around 0.5) between October and November SCE (see Fig. S1). European SCE anomalies are also present from October in the models, but not in observations. A significant retreat of the sea ice edge in the Barents Sea is also found for both models and observations in October and November and is also visible in December in the models.

The surface heat flux in lead and lag conditions can be used to discuss the processes leading to the atmospheric circulation response. The heat flux preceding the SCE is dominated by the atmospheric forcing of the snow cover, as for SST anomalies, while the heat flux lagging the SCE should primarily reflect the heat flux directly forced by the SCE (the thermodynamical component), although it could be strongly affected by the surface heat flux intrinsically associated with the atmospheric response (hereafter the dynamical heat flux component). At lag 0 , both effects play a role and may even cancel (Frankignoul et al. 1998). Since the surface heat flux responds rapidly to the surface conditions (simultaneously on monthly time scale), one can use in-phase relations to estimate the (thermodynamical) heat flux driven by the SCE anomalies, if the (larger) dynamical component is removed. To do so, we first calculate the 
a)

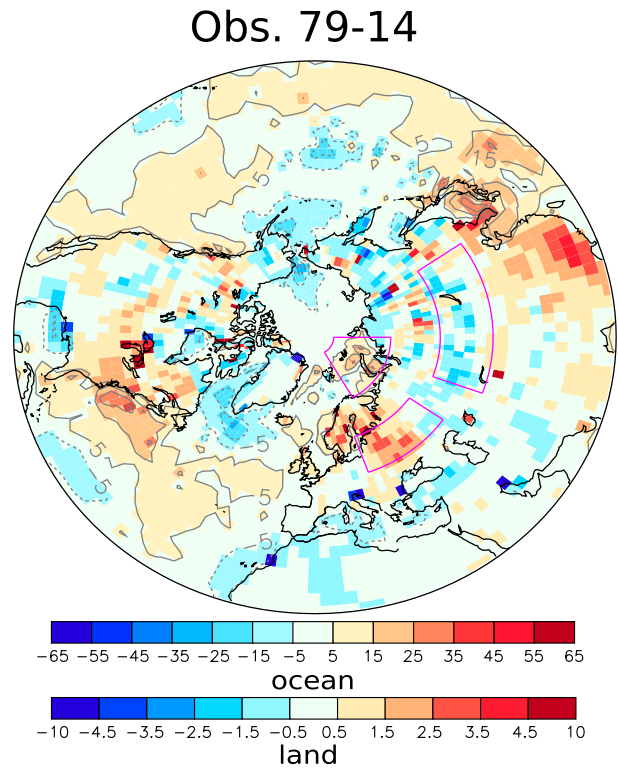

b) Models

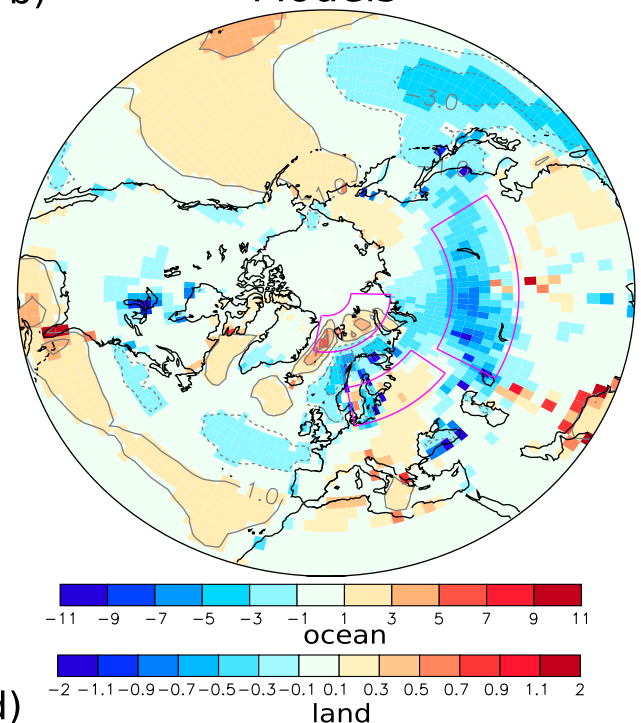

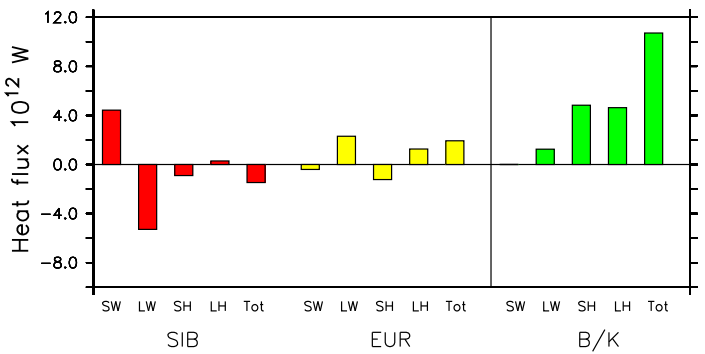

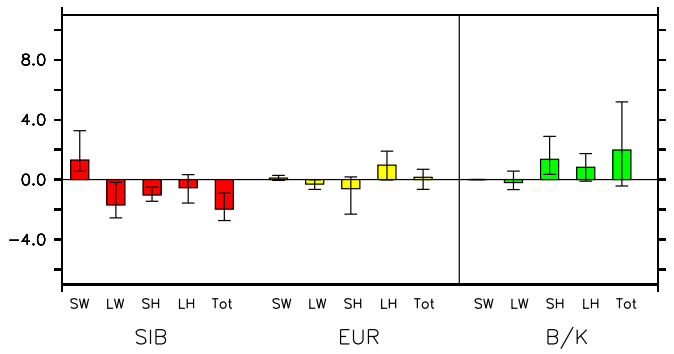

FIG. 9. November heat flux thermodynamical component, positive upward, in $\mathrm{W} \mathrm{m}^{-2}$, associated with the November MCA-snow index in (a) ERA-Interim and (b) the four models. The color scale is different over land and ocean to emphasize the changes over continental surfaces. Note the different contour intervals for ERA-Interim and models. Also shown are regressions of the shortwave (SW), longwave (LW), sensible (SH), latent (LH), and total (Tot) heat flux over Siberia (SIB), Europe (EUR), and the Barents-Kara Sea (B/K) integrated over boxes shown in (a) and (b) with histograms for (c) ERA-Interim and (d) the mean of the four models. In (d) the error bars indicate the minimum and maximum values among models.

heat flux by adding surface radiative and turbulent fluxes. A standardized atmospheric index, referred to as ATM, was computed by projecting the November SLP anomalies over $30^{\circ}-90^{\circ} \mathrm{N}, 80^{\circ} \mathrm{W}-180^{\circ} \mathrm{E}$ onto the SCAlike patterns shown in Fig. 4. The dynamical heat flux component corresponding to one standard deviation of the MCA-snow index is obtained by regressing the heat flux anomalies onto ATM, multiplied by the correlation between ATM and MCA-snow (shown in Fig. S2). The total heat flux anomaly associated with the SCE pattern in Fig. 3a is given by the regression of the heat flux onto MCA-snow (shown in Fig. S3), while the difference of the two (Figs. 9a,b) is an estimate of the thermodynamical effect. Figures $9 \mathrm{c}$ and $9 \mathrm{~d}$ illustrate such a thermodynamical component of the heat flux integrated over three boxes (see purple boxes in Figs. 9a,b) located over Siberia, Europe, and the Barents and Kara Seas.
The location of the boxes was adjusted to capture the snow and sea ice influences in models and observations.

In November, the heat flux changes induced by the snow cover are downward over a wide latitudinal band in central Siberia from Lake Balkhash to Sakhalin Island in ERA-Interim and models (Figs. 9a,b), although the results are noisy in ERA-Interim. This is consistent with a net cooling effect of positive snow cover anomalies, as the larger surface albedo leads to more reflected shortwave radiation, and as the surface may be more insulated from the warmer soil if the snow depth also increases (Orsolini et al. 2016). The cooler surface temperature results in a dominant reduction of longwave radiation and sensible heat flux. However, the turbulent fluxes have a larger contribution in models, while the longwave and shortwave components dominate in observations (Figs. 9c,d). Conversely, the heat 
flux anomalies are upward in ERA-Interim over eastern Europe and Scandinavia where the SCE decreases, whereas in models there is almost no net heating effect. Interestingly, over the Barents-Kara Seas, the heat flux is mainly upward over open water in the Nordic seas, which suggests a large heating of the atmosphere where the sea ice has retreated in November. This is consistent with an active influence of SIC anomalies onto the lower troposphere. However, while the total heat flux release over the Barents-Kara Seas is dominant in ERA-Interim, it is smaller and less robust in models. The same analysis applied to the December heat flux provides comparable results over Europe and Siberia (see Fig. S4), but the heating over the Barents-Kara Seas is larger in models, whereas a net cooling is obtained in observations. This is because the sea ice anomalies persist in December in models (see Fig. 8f), while they vanish in ERA-Interim (Fig. 8e).

In summary, the diabatic forcing of SCE anomalies is consistent in models and ERA-Interim, with cooling when the SCE increases. However, the diabatic heating from the SIC anomalies over the Barents-Kara Seas is larger, but it is also less robust than the one associated with SCE. As the surface heat flux anomalies are not assimilated in ERA-Interim and largely depend on the model physics, these results might be model dependent.

\section{c. Troposphere-stratosphere coupling}

We calculated the regressions of the SLP (Fig. 10), zonal-mean temperature, and geopotential height (Fig. 11) onto November MCA-snow, from October to January. In observations, the November SCE anomalies are preceded in October by a small anticyclone centered over the northern coast of Siberia (Fig. 10a), as in Cohen et al. (2002). In November, one month later, the SCA pattern (Fig. 10c) is visible, with cold tropospheric anomalies over Eurasia between $40^{\circ}$ and $60^{\circ} \mathrm{N}$, above the positive SCE anomalies, and warm tropospheric anomalies at $78^{\circ} \mathrm{N}$, at the location of the Barents-Kara Seas (Fig. 4). The zonal mean anomalies are largely barotropic below $300 \mathrm{hPa}$, which illustrates the main role of the tropospheric eddies for the SCA pattern. The anomalous anticyclone over Eurasia has been interpreted as a response to October Siberian snow cover, the snow-induced cooling acting to reinforce and expand westward the Siberian high (Cohen et al. 2007; Jeong et al. 2011; Orsolini et al. 2013). However, it can also be interpreted as a result of the stationary Rossby wave induced by the anomalous turbulent heat flux from the sea ice retreat in the BarentsKara Seas (e.g., Honda et al. 2009; García-Serrano et al. 2015), or as internal atmospheric variability since simultaneous relations primarily show the SCE forcing by the SCA. In the lower stratosphere, there is a warming over the polar cap $\left(75^{\circ}-90^{\circ} \mathrm{N}\right.$, between 300 and $\left.100 \mathrm{hPa}\right)$ and

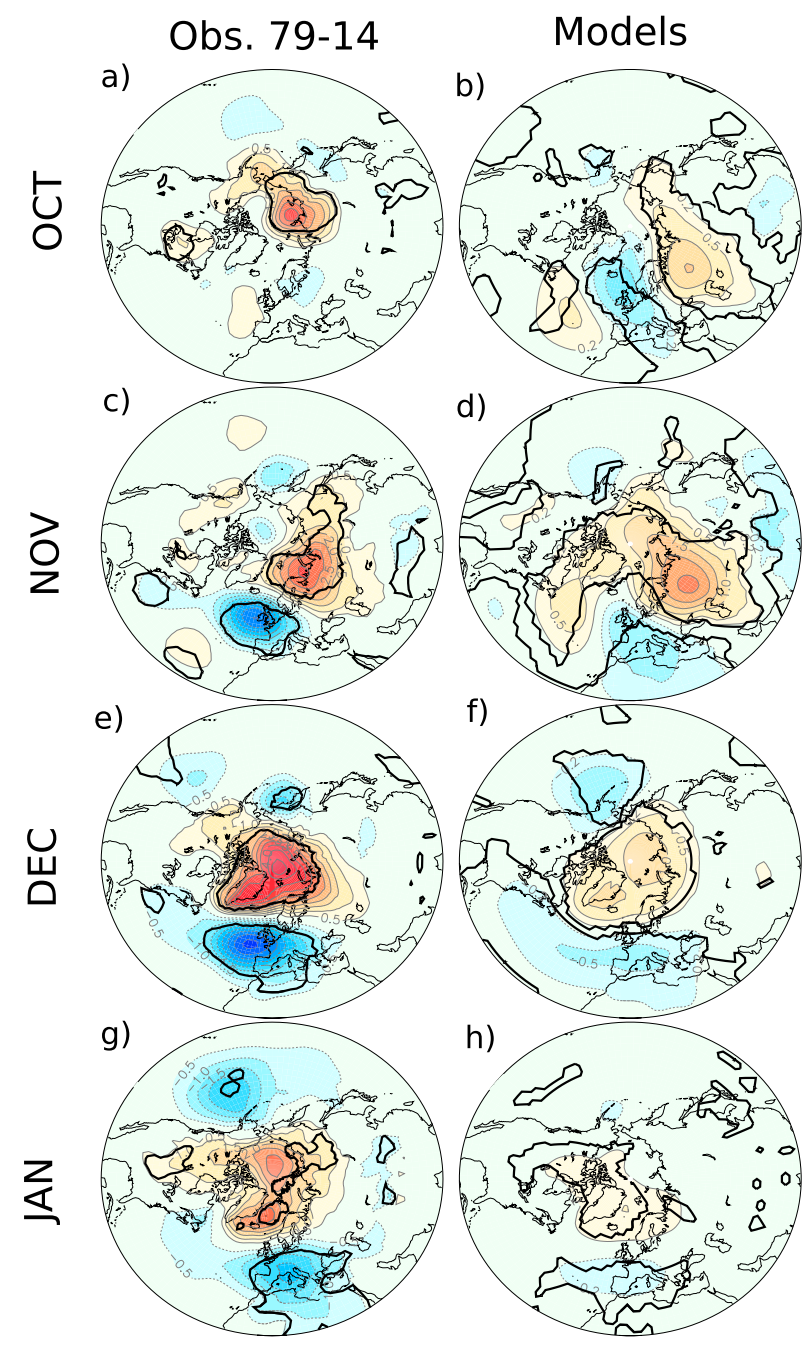

FIG. 10. Regression of the SLP (in hPa; contour interval $0.5 \mathrm{hPa}$ ), onto the MCA-snow index for (left) ERA-Interim and (right) models, in (a),(b) October, (c),(d) November, (e),(f) December, and $(\mathrm{g}),(\mathrm{h})$ January. The thick black line indicates $5 \%$ significance for observations or anomalies of the same sign among the four models. The contour interval at -0.2 and $0.2 \mathrm{hPa}$ was added for models.

positive geopotential height anomalies above (Fig. 11a) that indicate a weakening of the polar vortex. In December, one month later, a barotropic negative NAO/ AO pattern appears in the Euro-Atlantic region (Fig. 10e) while the polar vortex is further weakened, with stratospheric temperature anomalies above $100 \mathrm{hPa}$ that are only significant between $40^{\circ}$ and $65^{\circ} \mathrm{N}$ (Fig. 11c). The regressions are similar in January, with the SLP anomalies projecting on the AO (Fig. 10g) and stronger zonalmean geopotential height and temperature anomalies (Fig. 11e).

In the CMIP5 models, the atmospheric anomalies in October (Fig. 10b), which precede by one month the 
a)
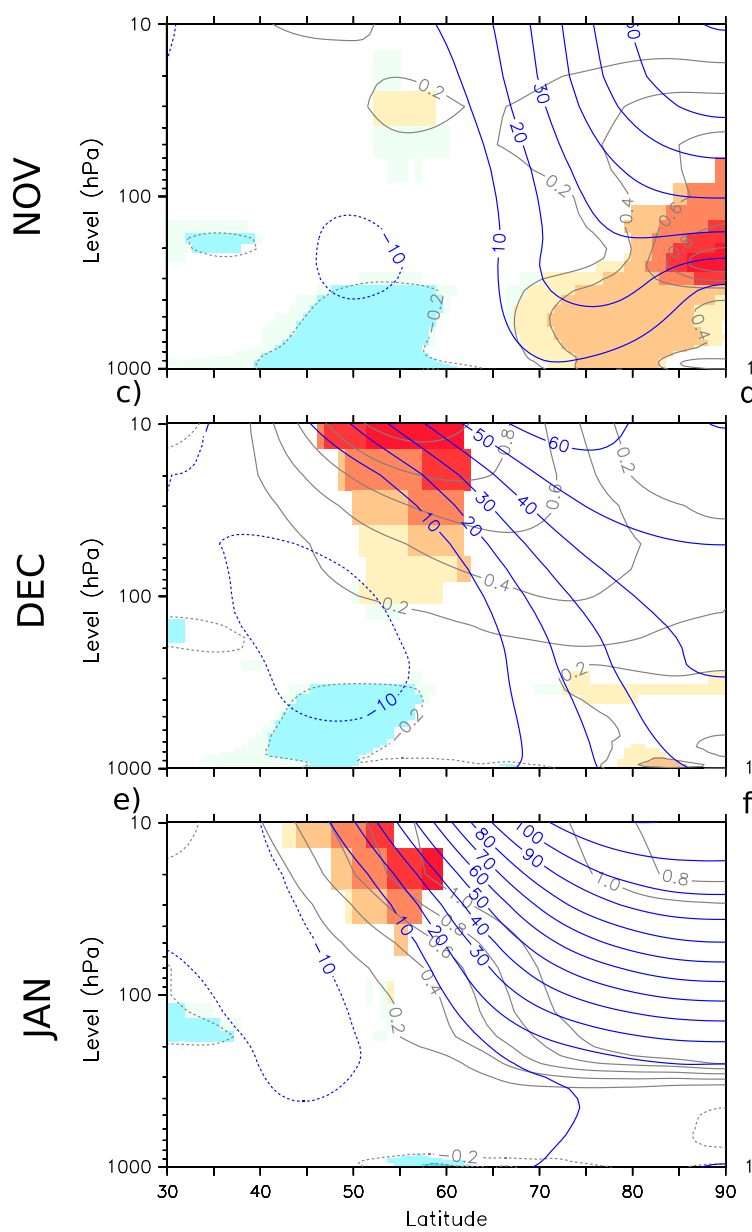

b)

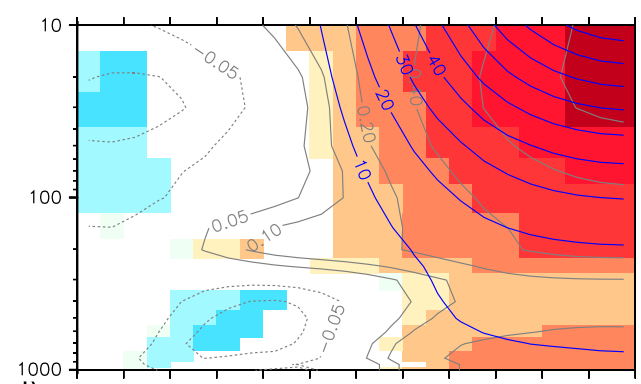

d)

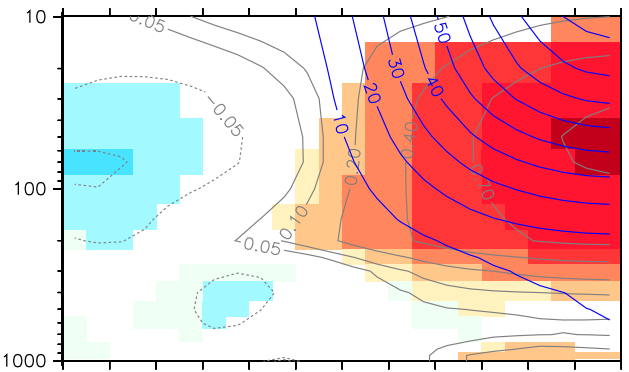

f)

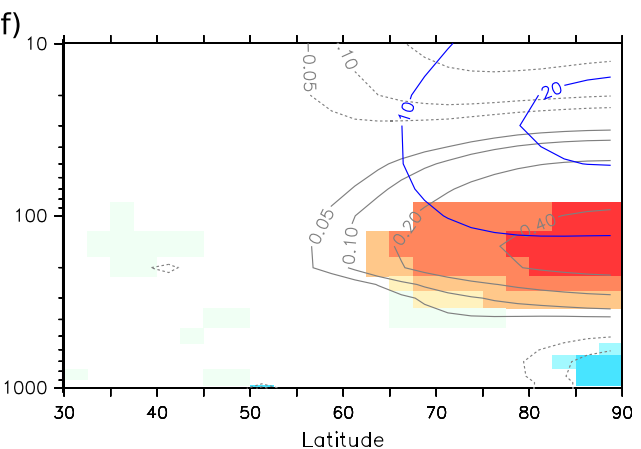

FIG. 11. Regression of the zonal-mean temperature (gray contours and color shading; in K) and geopotential height (blue contours; in m) onto the MCA-snow normalized index, for (left) ERA-Interim and (right) models, in (a),(b) November, (c),(d) December, and (e),(f) January. Colors indicate zonal mean temperature (left) with a level of significance below $10 \%$ or (right) anomalies of the same sign among the four models.

SCE anomalies, show alternating trough and ridges from the North Atlantic to southeastern Asia, with anticyclonic anomalies over the Urals and a depression over northern Europe, clearly indicative of a stationary wave and already reminiscent of the SCA pattern. In November, the anomalies are more complex and larger, with a dominant anticyclonic circulation over the Urals extending into the Arctic (Fig. 10d), so that the Siberian high is clearly intensified and shifted westward, while the SLP response is AO-like in December and, to a lesser extent, in January. The temperature anomalies show a large warming in the lower troposphere north of $70^{\circ} \mathrm{N}$ (Figs. 11b,d) from November to December, and display an important warming in the polar stratosphere that persists into January only in the lowermost stratosphere at $200 \mathrm{hPa}$. The warm anomalies are rather baroclinic in the polar troposphere, which is consistent with the influence of Arctic SIC reduction noted in Cattiaux and Cassou (2013). In November and December, there are also cold temperature anomalies below $400 \mathrm{hPa}$ south of the positive SCE anomalies, likely associated with the cold temperature found over Siberia where the snow cover increases (Figs. 10b,d). In models, both the tropospheric NAO/AO pattern and the anomalies in the stratosphere are smaller during January, but they are still significant (Figs. 10h and 11f).

The troposphere-stratosphere coupling is further illustrated by the polar cap temperature $\left(65^{\circ}-90^{\circ} \mathrm{N}\right)$ regression onto the MCA-snow index in Fig. 12. For observations, the daily air temperature was used, while only monthly data were available for models. The observations show a warming in the lower stratosphere 
a)

Obs.

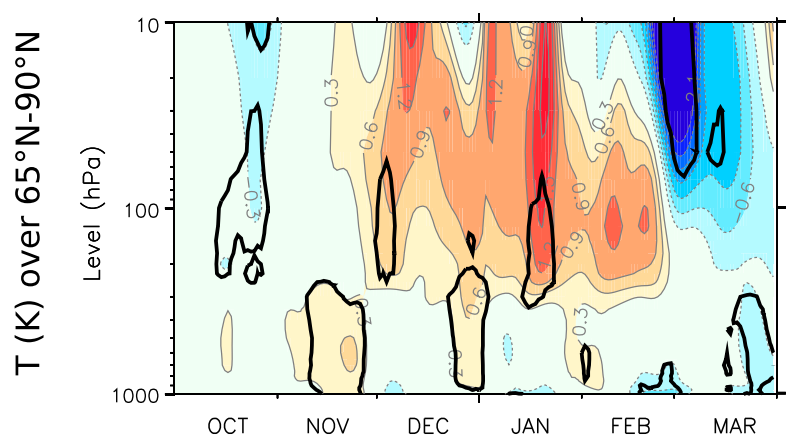

b)

Models

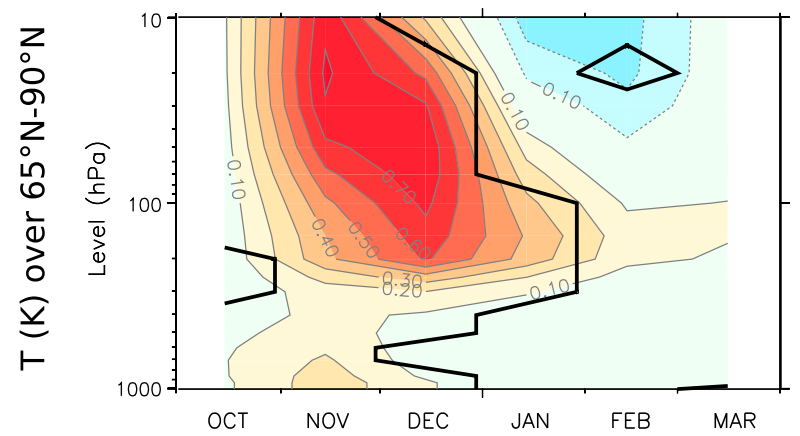

FIG. 12. Regression of the temperature over the polar cap $\left(65^{\circ}-\right.$ $90^{\circ} \mathrm{N}$ ) onto the MCA-snow normalized index, for (a) ERA-Interim and (b) models. The thick black lines indicate (a) level of significance below $10 \%$ or (b) anomalies of the same sign among the four models. Note the different contour intervals in (a) and (b).

between 200 and $70 \mathrm{hPa}$ from December to February, as found by Cohen et al. (2014b) and Orsolini et al. (2016), but it is only $10 \%$ significant for a few days in early December and January. There are also hints of downward propagation in late December and late January. In models, the polar cap temperature anomalies are only half the ones observed. The timing is different as the warming starts in November, one month earlier, and the downward propagation is faster in the stratosphere with little penetration into the troposphere.

In summary, the diabatic heating from the November SCE and, possibly, SIC anomalies is associated with a stationary wave pattern that weakens the polar vortex. Particularly in observations, the AO changes obtained one and two months later are consistent with the downward propagation of polar vortex weakening. Next, we will establish the relative importance of the SIC and SCE anomalies.

\section{d. Link with sea ice anomalies}

To compare the role of SIC and SCE, we also perform a MCA using SIC over the Barents-Kara Sea $\left(65^{\circ}-85^{\circ} \mathrm{N}\right.$,
TABLE 2. Statistics of different MCAs using December SLP as the left field, and November snow cover (SCE), sea ice concentration (SIC), concatenated SCE and SIC (SCE+SIC), or concatenated SCE, SIC and Eurasian SLP (SCE+SIC+SLP Eur $_{2}$ as the right field. For the models, the mean over the four selected models is given. The level of significance is given in parentheses for observation (see section $2 \mathrm{c}$ for details). For climate models, the number in parentheses indicates the number of models, out of four, where the level of significance is equal to or below $10 \%$.

\begin{tabular}{llllll}
\hline \hline & \multicolumn{2}{c}{ OBS } & & \multicolumn{2}{c}{ Models } \\
\cline { 2 - 3 } \cline { 5 - 6 } & NSC & \multicolumn{1}{c}{$R$} & & NSC & $R$ \\
\hline SCE & $2.5(0 \%)$ & $0.82(1 \%)$ & & $0.10(4 / 4)$ & $0.23(4 / 4)$ \\
SIC & $2.9(3 \%)$ & $0.61(18 \%)$ & & $0.14(1 / 4)$ & $0.14(1 / 4)$ \\
SCE+SIC & $2.4(0 \%)$ & $0.75(2 \%)$ & & $0.10(2 / 4)$ & $0.16(0 / 4)$ \\
SCE+SIC+SLP & $2.1(0 \%)$ & $0.78(0 \%)$ & & $0.14(4 / 4)$ & $0.24(4 / 4)$ \\
\hline
\end{tabular}

$15^{\circ}-100^{\circ} \mathrm{E}$ ) in November and SLP in December. We additionally perform MCA using both November SIC and SCE concatenated into a single predictor field, with SLP as predictand field. The results are summarized in Table 2. When only using November SIC as predictor, the NSC is highly significant, but the correlation $R$ is lower than when using SCE, and not significant at the $10 \%$ level, as in García-Serrano et al. (2015; see also Fig. S5). On the other hand, using concatenated SCE and SIC predictors is as significant as with SCE alone, and the MCA patterns (Fig. 13a) show that the snow dipolar anomalies and the sea ice retreat in the Barents-Kara Seas precede a negative AO-like pattern in December, which is consistent with previous results (Fig. 8), but for larger SIC changes. Interestingly, SCE and SIC seem to contribute similarly to the SLP response in Fig. 13. Indeed, projecting SIC anomalies onto the SIC part of the MCA covariance map (referred to as MCAcat_SIC) and SCE anomalies onto the SCE part (referred to as MCAcat_SCE) yields two well-correlated time series $(0.58$, significant at the $5 \%$ level) that compare well with the atmospheric December MCA time series (Fig. 13b).

To evaluate the relative influence of the SCE and SIC pattern, we used the time series associated with the SCE and SIC fields in the SCE/SLP (MCA-snow) and SIC/SLP (referred to as MCA-SIC) individual MCA, respectively, to separate more clearly the SIC and SCE influences. These two time series have a correlation of 0.42 , and a bivariate regression of the SLP using these two time series shows little multicollinearity (variance inflation factor of 1.4). The regression slopes (Fig. 14) show that the SCE holds a larger signal in observations, which is consistent with the higher correlation in the MCA analysis (see Table 2). The SIC has a similar influence, but its amplitude is twice smaller, and it is less significant. These results are not substantially modified when using other indices for SCE or SIC. 
a) $\mathrm{NSC}=2.43(0 . \%) \quad \mathrm{R}=0.75(2 . \%) \mathrm{SCF}=54.1 \%$
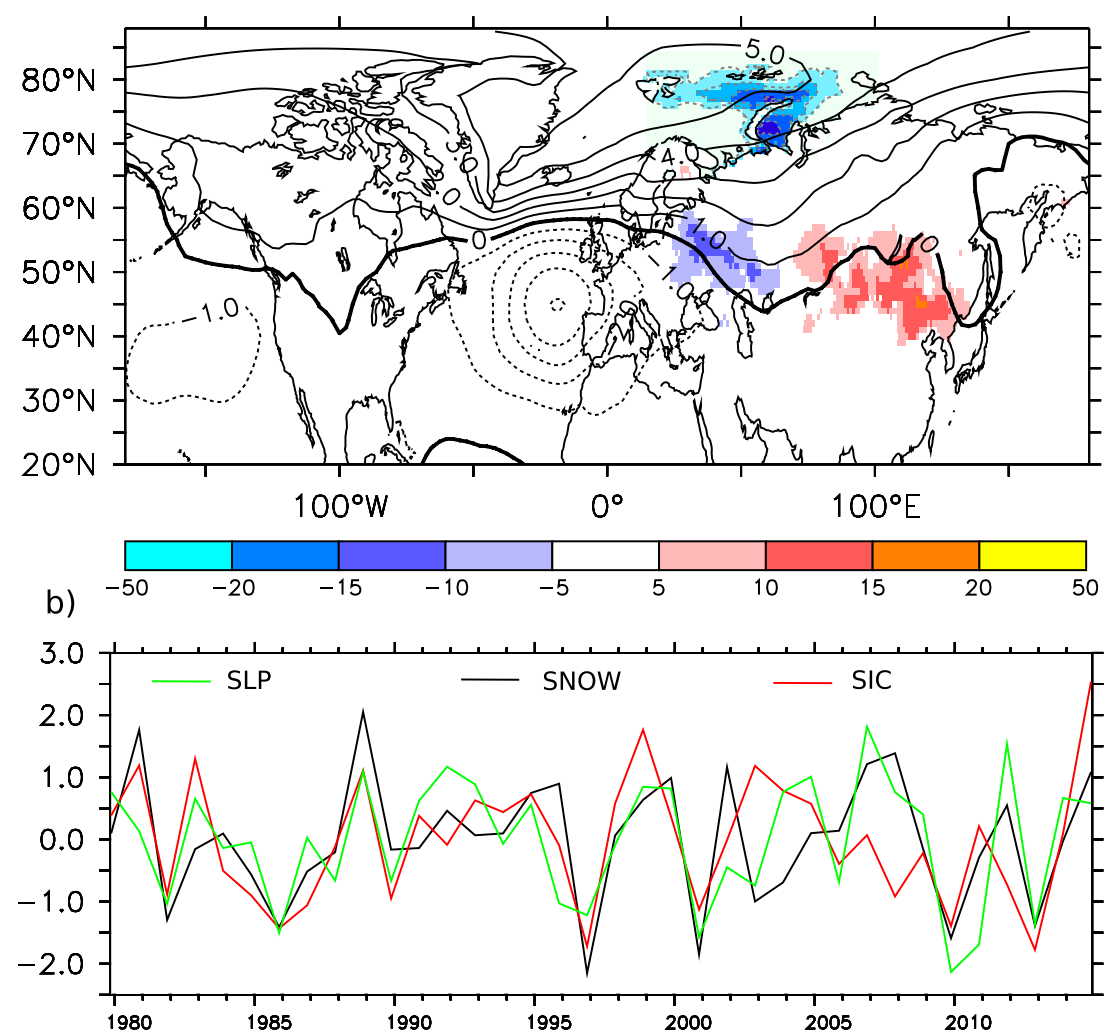

FIG. 13. (a) Snow cover (color over land; in \%) and SIC (color over ocean; in \%; contour interval 5\%) homogeneous covariance map and SLP (in hPa) heterogeneous map for the first MCA mode using combined snow/sea ice in November and SLP in December for ERA-Interim. (b) MCAcat_SCE (black), MCAcat_SIC (red), and atmospheric SLP yearly time series (green) from the MCA (normalized).

The concatenated MCA yields similar results for the four models, with an SCE dipole and a decrease of SIC in November preceding the December AO (not shown), although the NSC and correlation are much lower, and adding SIC to SCE (or considering SIC alone) strongly degrades the levels of significance (Table 2). Yet, the correlation between the MCAcat_SCE and MCAcat_SIC time series (Table 3 ) is significant in each model, even if it is lower than in observations, which can be explained by the different sampling, the smaller SCA occurrence, or model biases such as the colder mean state in preindustrial climate, which allows less Barents-Kara SIC variability. However, these significance tests are biased since the four models were selected based on their response to SCE, not to SIC, and other CMIP5 models are more sensitive to SIC (García-Serrano et al. 2017).

The same analysis was conducted using SIC anomalies in early autumn (September or October) together with November SCE (Table S2), which provides significant results only when using October SIC, with patterns as in Fig. 13, but smaller NSC and $R$. We also repeated the analysis using November SIC/SCE and SLP in January and February (Table S3), as the stratospheric pathway is also important during late winter (Kim et al. 2014; Jaiser et al. 2016), but the MCA results are much less significant in the observations.

\section{e. Link with the Scandinavian pattern}

The upward influence of tropospheric planetary waves into the stratosphere due to atmospheric dynamics, such as during blocking situations, can also explain that the SCA is followed by an AO-like pattern one month later, without any influence of surface diabatic heating (Kuroda and Kodera 1999; Takaya and Nakamura 2008; Martius et al. 2009; Woollings et al. 2010). To test the influence of such tropospherestratosphere coupling, we use an MCA with Eurasian $\operatorname{SLP}\left(45^{\circ}-85^{\circ} \mathrm{N}, 0^{\circ}-150^{\circ} \mathrm{E}\right)$, Eurasian SCE, and BarentsKara SIC in November concatenated as the predictor 

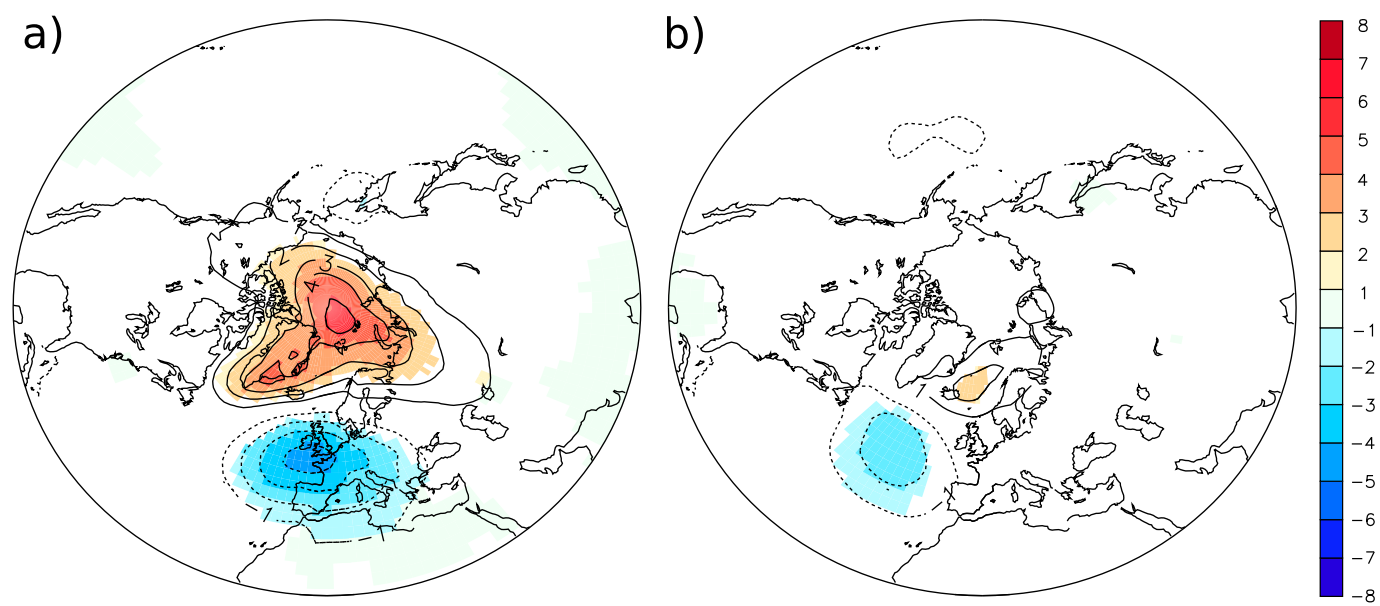

FIG. 14. Regression slopes of a bivariate regression of the December SLP (in hPa) for the (a) MCA-snow and (b) MCA-SIC indices. Colors indicate level of significance below $10 \%$.

field, and Northern Hemisphere SLP in December as the predictand field. For the sake of simplicity, the ENSO variability was not removed in the analysis. In both observations and models, the results of this MCA are strongly significant (Table 2), and the covariance maps are similar to Fig. 13, with the homogeneous SLP covariance map in November resembling the SCA (not shown).

We next examine the time series of the three November predictors (SCE dipole, Barents-Kara SIC, and SCA). The time series associated with the SCE and SIC fields are obtained as before from the SCE/SLP (MCAsnow) and SIC/SLP (MCA-SIC) individual MCAs, whereas the SCA index is given by the first rotated EOF of the Eurasian SLP $\left(45^{\circ}-85^{\circ} \mathrm{N}, 0^{\circ}-150^{\circ} \mathrm{E}\right)$ in November. To distinguish the impact of each predictor, a multivariate regression of the December SLP on the three predictors is done, noting that, despite the large correlation between predictors, multicollinearity is limited (variance inflation factors $<2.0$ ). The results (Figs. 15a-c) again show that the SCE dipole has the largest influence on SLP in December, while the SIC provides weaker but significant anomalies as in the bivariate regression in Fig. 14. The SCA seems to be also important for the SLP over the British Isles or Alaska, but the anomalies are weaker and not significant. A similar multivariate regression using an $\mathrm{AO}$ index, as given by the first EOF of December SLP, is shown in Fig. 15d. Again, the SCE appears to be the best predictor of the AO, followed by the SIC, while the SCA has the lowest $R^{2}$. Taking the three indices as predictors with a multivariate regression only slightly improves the variance explained by the SCE alone. In the four models (Fig. 15d; symbols using the right vertical axis), the same analysis also shows that the SCE dipole still plays the dominant role in three models, while the SIC has a dominant influence only in one model (CanESM). In all models, the SCA pattern also appears as a good predictor of the AO. This suggests that, in these models selected based on their response to SCE, internal atmospheric dynamical processes may also explain the statistical relationship found among SCE, SIC, and the atmosphere one month later, and hence explain why the influence of SCE and SIC is underestimated. These conclusions are not substantially modified when using other indices for the AO, the snow dipole or the Barents-Kara SIC anomalies.

\section{Discussions and conclusions}

We have investigated the links between Eurasian SCE and the atmosphere in observations during 1979-2014 and CMIP5 models. We found that a dipole of snow cover anomalies in November with positive (negative) snow cover anomalies over eastern Siberia (eastern Europe) precedes a negative AO-like pattern in December, one month later. The largest statistical links are found when considering November SCE, as in Orsolini et al. (2016), but other studies focus more on October snow cover (Cohen and Entekhabi 1999; Cohen et al.

TABLE 3. Correlation between MCAcat-SCE and MCAcat-SIC time series. The bold numbers indicate $1 \%$ significance.

\begin{tabular}{lc}
\hline \hline \multicolumn{1}{c}{ Data } & Correlation \\
\hline Observations & $\mathbf{0 . 5 8}$ \\
CanESM2 & $\mathbf{0 . 2 6}$ \\
GISS-E2-R & $\mathbf{0 . 2 4}$ \\
MPI-ESM-LR & $\mathbf{0 . 4 0}$ \\
CESM1-BGC & $\mathbf{0 . 2 7}$ \\
\hline
\end{tabular}


a)

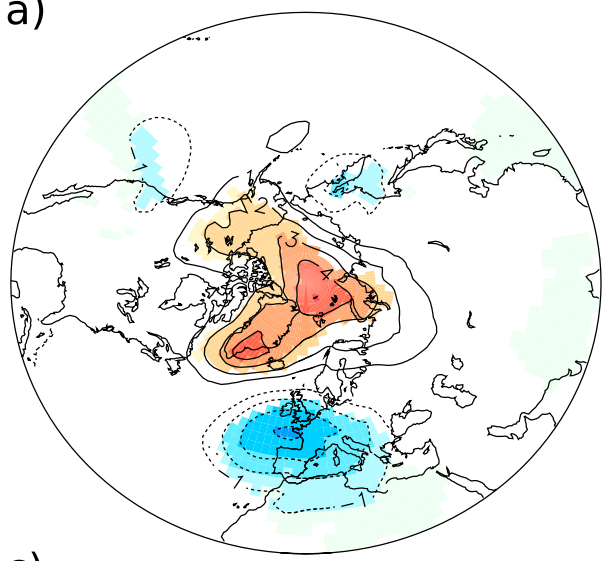

C)

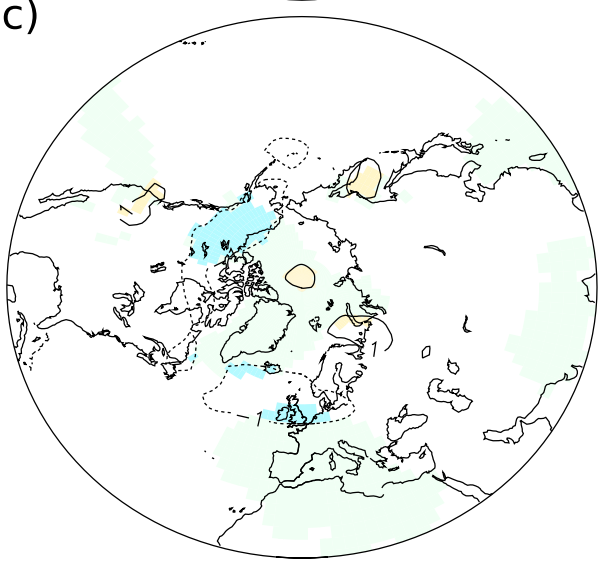

b)

d)

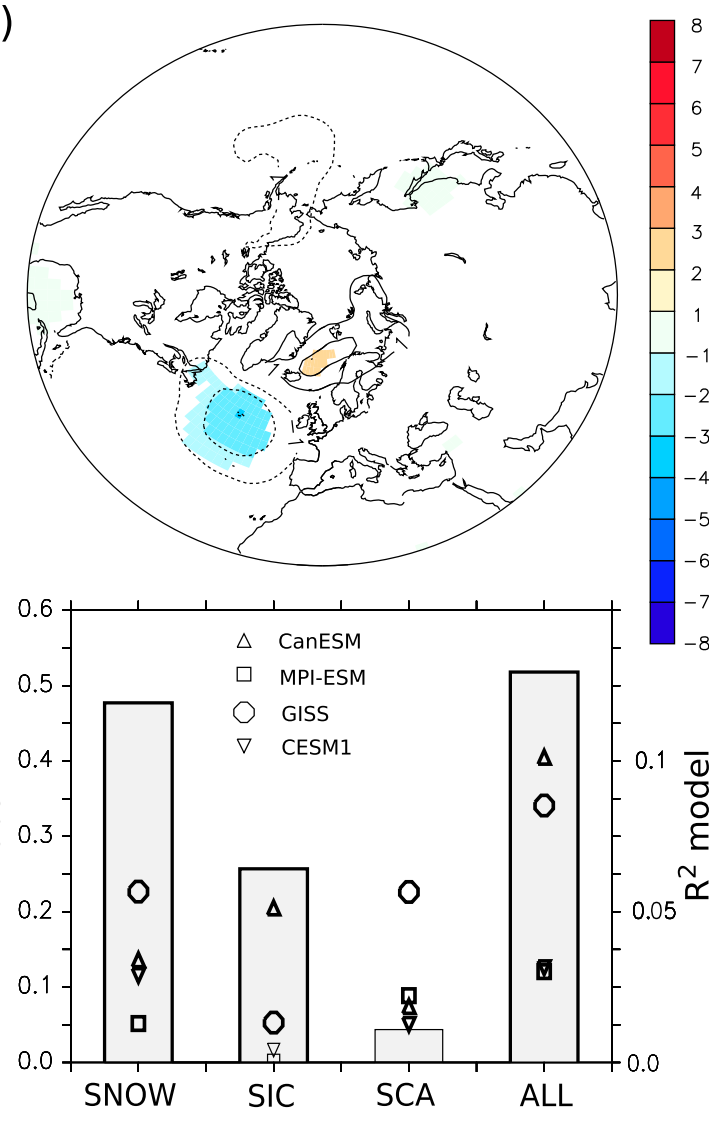

FIG. 15. Regression slopes of a multivariate regression of the SLP (in hPa) onto the (a) snow dipole, (b) Barents-Kara Sea SIC, and (c) SCA indices. In (a)-(c) colors indicate level of significance below $10 \%$. (d) $R^{2}$ value of univariate regressions using the $\mathrm{AO}$ index as predictand and snow dipole, Barents-Kara Sea SIC, or SCA as predictor. ALL indicates the $R^{2}$ when using the three indices in a multivariate regression. Note that the $y$ axis is different for observation (bars, left axis) and models (symbols, right axis). The black symbols (bars) provide the results for models (observations), with thick symbols (bars) indicating a level of significance of $R^{2}$ below $10 \%$.

2007; Cohen and Jones 2011; Handorf et al. 2015). Lagged regression actually reveals that the November SCE is related to similar anomalies in October, but statistical significance is too limited with the MCA using October SCE. The choice of the dataset, the methodology, and the period considered might explain this discrepancy (see the appendix). The CMIP5 models, in general, fail to simulate this potential effect of snow cover. Nevertheless, a weaker, but similar, relationship between the SCE and the AO is present in four models: CanESM, MPI-ESM-LR, GISS-E-R, and CESM-BGC.

The models and ERA-Interim indicate that downward (upward) heat flux anomalies are simulated over positive (negative) snow cover anomalies over Siberia (Europe) during November. We verified that eastern Siberia pole of the snow dipole anomalies has the best relationship with the $\mathrm{AO}$ one month later both in observations and models, so that the SCE over Siberia seems to have the largest influence. The diabatic cooling of the troposphere over Siberia is consistent with the intensification and westward expansion of the Siberian high. This may lead to a polar vortex weakening from November to January driven by upward planetary wave activity flux, as found previously in observations (Saito et al. 2001; Handorf et al. 2015; Furtado et al. 2016) and in sensitivity experiments using SCE anomalies (Gong et al. 2004; Fletcher et al. 2009; Peings et al. 2012; Orsolini et al. 2013, 2016). Here, we show that the same process can be verified qualitatively using multicentennial control climate model simulations, although the SCE influence is much weaker.

The atmospheric pattern responsible for the variability of the snow cover dipole is the Scandinavian 
a)

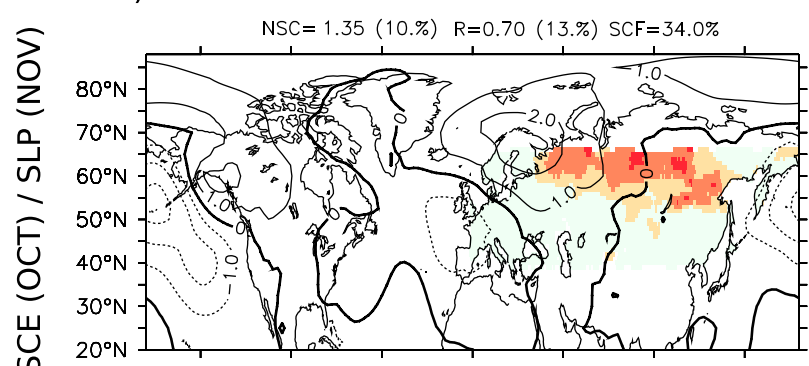

c)

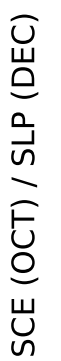

Obs. 1979-2014

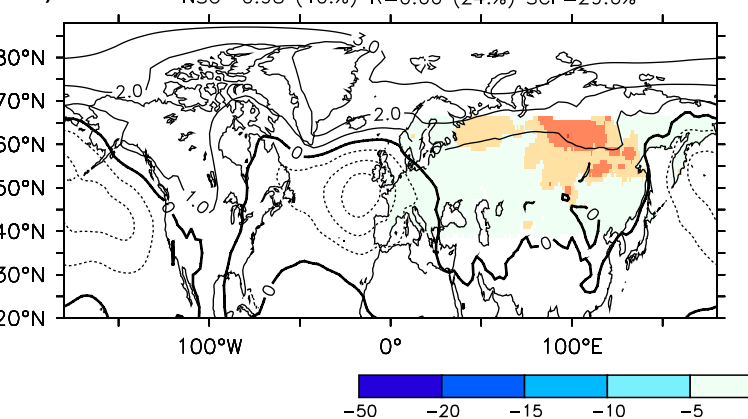

b)

Obs. 1979-2005

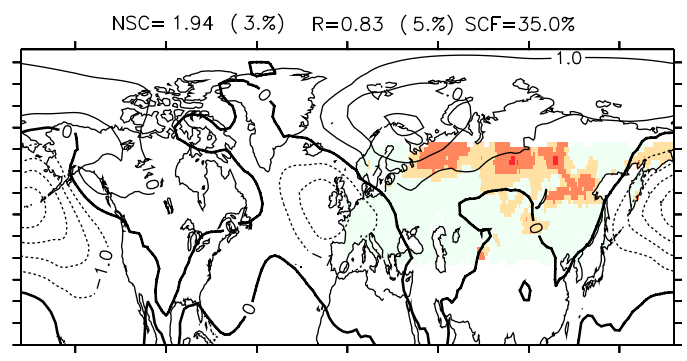

d)

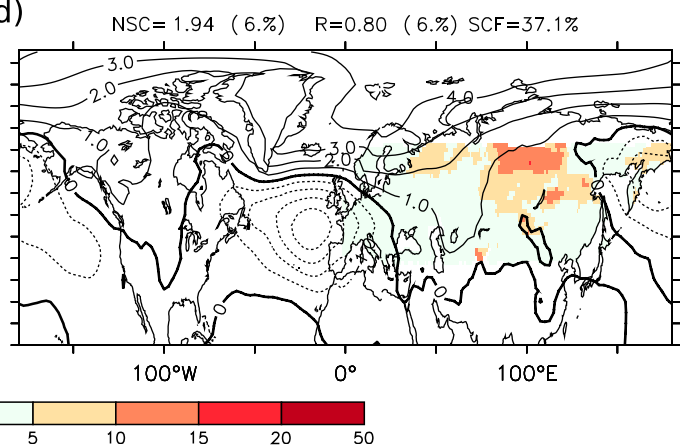

FIG. A1. (a) Homogeneous October snow cover fraction (in \%) and November heterogeneous SLP (in hPa) covariance maps for the first MCA mode, when the snow cover leads the atmosphere by one month, for ERA-Interim during 1979-2014. (b) As in (a), but for the 1979-2005 period. (c) As in (a), but using the December SLP. (d) As in (c), but for the 1979-2005 period.

pattern [SCA, as in Bueh and Nakamura (2007)], with a large anticyclone over the Urals. Such anticyclone leads to northerly cold advection east of the anticyclone, bringing cold air over Siberia and southerly warm advection over central Europe and the Barents and Kara Seas. The SCA forcing explains that the Barents-Kara SIC and Eurasian SCE are largely correlated (Wegmann et al. 2015; Furtado et al. 2016). We find that the models produce less frequent SCA-like and more frequent AO-like events, possibly linked to blocking processes that are not well simulated in low-resolution models (Dawson et al. 2012), but this could also be due to natural atmospheric variability. Deficiencies in the simulation of the SCA characteristics in models might therefore explain the weaker SCE influence in models. In addition, the upward heat flux driven by a retreat of the sea ice in the Barents-Kara Seas is weaker and less robust in the models than in ERA-Interim, perhaps explaining why the SIC influence is also underestimated in the four models that simulate the SCE impacts.

An MCA using SLP and combined SCE and SIC suggests that November SCE and SIC forcing provide similar covariability with the December AO in observations. However, a bivariate regression reveals that the SCE dipole is a much better predictor than the BarentsKara SIC anomaly. As the SCE and the SIC variability are linked, both fields might constructively interfere to weaken the polar vortex, as suggested in Cohen et al. (2014a), although the surface forcing from the snow cover anomalies might be dominant. On the other hand, the November SIC in models has an impact on the AO in only one model, perhaps because they were selected based on their representation of the SCE influence. When investigating more systematically the links between Greenland-Barents-Kara SIC and the NAO/AO in CMIP5 models, García-Serrano et al. (2017) did find a robust SIC influence, but they noted that the timing and/ or the processes for the SIC influence are model dependent. Here, the lack of links between November SIC and December atmosphere may result from our selection of the models based on their representation of the SCE impact (and not SIC impact) and also from the model averaging that may mix different behavior among models. The weaker SCE influence in models and the lack of links between the SCE and SIC is consistent with the underestimated troposphere-stratosphere coupling in models, as found in Furtado et al. (2015). However, it can also be explained by the poor simulation of the SCA variability, the colder climate in preindustrial control simulation, or natural climate variability.

A better understanding of the coupling between land snow cover, Arctic sea ice, and the atmosphere 
TABLE A1. Statistics of the MCA using October snow cover and SLP in following months, using different time periods (79-05: from 1979 to 2005; 79-11: from 1979 to 2011; and 79-14: from 1979 to 2014), and atmospheric months (NOV: November; DEC: December; DJF: December-February). The level of statistical significance is given in parentheses.

\begin{tabular}{ccll}
\hline \hline Period & SLP season & \multicolumn{1}{c}{ NSC } & \multicolumn{1}{c}{$R$} \\
\hline $79-14$ & NOV & $1.3(10 \%)$ & $0.70(13 \%)$ \\
$79-14$ & DJF & $1.1(29 \%)$ & $0.63(32 \%)$ \\
$79-05$ & NOV & $1.9(3 \%)$ & $0.83(5 \%)$ \\
$79-05$ & DEC & $1.9(6 \%)$ & $0.80(6 \%)$ \\
$79-05$ & DJF & $2.4(6 \%)$ & $0.71(25 \%)$ \\
$79-11$ & NOV & $1.1(27 \%)$ & $0.77(21 \%)$ \\
$79-11$ & DEC & $1.6(9 \%)$ & $0.71(27 \%)$ \\
$79-11$ & DJF & $1.5(11 \%)$ & $0.66(44 \%)$ \\
\hline
\end{tabular}

using dedicated climate model experiments would be necessary to properly assess the causality links and better discriminate between their influences on the winter AO. Nonetheless, the methodology used here could be applied to climate projection of the twenty-first century in order to investigate how the polar amplification of global warming will modify the links between the atmosphere and Arctic surface conditions.

Acknowledgments. The research leading to these results has received funding from the Blue-Action project (the European Union's Horizon 2020 research and innovation programme, Grant 727852). Javier GarcíaSerrano also received funding from a H2020-funded DPETNA grant (MSCA-IF-EF 655339). We thank the European Centre for Medium-Range Weather Forecasts for providing the ERA-Interim reanalysis, Rutgers University for providing the observed snow cover fields, and the National Snow and Ice Data Center for providing the sea ice extent. For their role in producing, coordinating, and making available CMIP5 model outputs, we acknowledge the climate modeling groups, the World Climate Research Programme's Working Group on Coupled Modelling and the Global Organization for Earth System Science Portals. This study benefited from the IPSL mesocenter facility, which is supported by CNRS, UPMC, Labex L-IPSL, which is funded by the ANR (Grant ANR-10-LABX-0018), and by the European FP7 IS-ENES2 project (Grant 312979).

\section{APPENDIX}

\section{October Snow Cover Influence}

The influence of October SCE on the atmosphere is discussed by using the MCA results, when SLP lags by one month, although statistical significance is limited (see Fig. 1). The covariance maps (Fig. A1a) show that increasing October SCE over northern Eurasia precedes a SLP pattern in November that has some resemblance with the SCA, plus a deeper Aleutian low. This differs from the negative AO found later, from December to February. It might be due to the snow data used, as many previous studies used a more integrated snow index, such as the Eurasian snow cover areal extent (e.g., Cohen et al. 2007; Cohen and Fletcher 2007). It could be due to differences in methodology, as Furtado et al. (2016) used multivariate EOF. It could also be due to nonstationarity (Peings et al. 2013). For instance, Cohen et al. (2007) considered the 1948-2004 period and Cohen and Fletcher (2007) the 1972-2005 one, whereas we focus on 1979-2014.

To investigate the possible influence of nonstationarity, we performed the MCA in different subperiods (Table A1). The most significant influence of October snow cover on SLP is found for November in the 19792005 period, as used in Cohen and Fletcher (2007); the MCA mode is also significant for December SLP, with an MCA pattern (Fig. A1d) sharing a large similarity with previous studies (i.e., Handorf et al. 2015). However, the levels of significance are limited when the DJF atmosphere is considered. If $1979-2011$ or 1979-2014 is used, significance is lost. Hence, the detected influence of the October snow cover is sensitive to the period.

\section{REFERENCES}

Allen, R. J., and C. S. Zender, 2010: Effects of continentalscale snow albedo anomalies on the wintertime Arctic oscillation. J. Geophys. Res., 115, D23105, doi:10.1029/ 2010JD014490.

Barnett, T. P., L. Dümenil, U. Schlese, E. Roeckner, and M. Latif, 1989: The effect of Eurasian snow cover on regional and global climate variations. J. Atmos. Sci., 46, 661-686, doi:10.1175/ 1520-0469(1989)046<0661:TEOESC $>2.0$. CO;2.

Barnston, A. G., and R. E. Livezey, 1987: Classification, seasonality and persistence of low-frequency atmospheric circulation patterns. Mon. Wea. Rev., 115, 1083-1126, doi:10.1175/ 1520-0493(1987)115<1083:CSAPOL > 2.0.CO;2.

Bretherton, C. S., C. Smith, and J. M. Wallace, 1992: An intercomparison of methods for finding coupled patterns in climate data. J. Climate, 5, 541-560, doi:10.1175/ 1520-0442(1992)005<0541:AIOMFF $>2.0 . C O ; 2$.

Bueh, C., and H. Nakamura, 2007: Scandinavian pattern and its climatic impact. Quart. J. Roy. Meteor. Soc., 133, 2117-2131, doi:10.1002/qj.173.

Cattiaux, J., and C. Cassou, 2013: Opposite CMIP3/CMIP5 trends in the wintertime northern annular mode explained by combined local sea ice and remote tropical influences. Geophys. Res. Lett., 40, 3682-3687, doi:10.1002/grl.50643.

- H. Douville, and Y. Peings, 2013: European temperatures in CMIP5: Origins of present-day biases and future uncertainties. Climate Dyn., 41, 2889-2907, doi:10.1007/s00382-013-1731-y. 
Close, S., M.-N. Houssais, and C. Herbaut, 2015: Regional dependence in the timing of onset of rapid decline in Arctic sea ice concentration. J. Geophys. Res. Oceans, 120, 8077-8098, doi:10.1002/2015JC011187.

Cohen, J., 1994: Snow cover and climate. Weather, 49, 150-156, doi:10.1002/j.1477-8696.1994.tb05997.x.

— Northern Hemisphere climate predictability. Geophys. Res. Lett., 26, 345-348, doi:10.1029/1998GL900321.

—, and C. Fletcher, 2007: Improved skill of Northern Hemisphere winter surface temperature predictions based on land-atmosphere fall anomalies. J. Climate, 20, 4118-4132, doi:10.1175/JCLI4241.1.

- , and J. Jones, 2011: A new index for more accurate winter predictions. Geophys. Res. Lett., 38, L21701, doi:10.1029/ 2011GL049626.

— D. Salstein, and K. Saito, 2002: A dynamical framework to understand and predict the major Northern Hemisphere mode. Geophys. Res. Lett., 29, 1412, doi:10.1029/2001GL014117.

—, M. Barlow, P. J. Kushner, and K. Saito, 2007: Stratospheretroposphere coupling and links with Eurasian land surface variability. J. Climate, 20, 5335-5343, doi:10.1175/2007JCLI1725.1.

, J. C. Furtado, M. A. Barlow, V. A. Alexeev, and J. E. Cherry, 2012: Arctic warming, increasing snow cover and widespread boreal winter cooling. Environ. Res. Lett., 7, 014007, doi:10.1088/1748-9326/7/1/014007.

— , and Coauthors, 2014a: Recent Arctic amplification and extreme mid-latitude weather. Nat. Geosci., 7, 627-637, doi:10.1038/ngeo2234.

J. C. Furtado, J. Jones, M. Barlow, D. Whittleston, and D. Entekhabi, 2014b: Linking Siberian snow cover to precursors of stratospheric variability. J. Climate, 27, 5422-5432, doi:10.1175/JCLI-D-13-00779.1.

Comiso, J. C., 2012: Large decadal decline of the Arctic multiyear ice cover. J. Climate, 25, 1176-1193, doi:10.1175/JCLI-D-11-00113.1.

Czaja, A., and C. Frankignoul, 2002: Observed impact of Atlantic SST anomalies on the North Atlantic Oscillation. $J$. Climate, 15, 606-623, doi:10.1175/1520-0442(2002)015<0606: OIOASA $>2.0 . \mathrm{CO} ; 2$.

Dawson, A., T. N. Palmer, and S. Corti, 2012: Simulating regime structures in weather and climate prediction models. Geophys. Res. Lett., 39, L21805, doi:10.1029/2012GL053284.

Dee, D. P., and Coauthors, 2011: The ERA-Interim reanalysis: Configuration and performance of the data assimilation system. Quart. J. Roy. Meteor. Soc., 137, 553-597, doi:10.1002/ qj. 828.

Déry, S. J., and R. D. Brown, 2007: Recent Northern Hemisphere snow cover extent trends and implications for the snowalbedo feedback. Geophys. Res. Lett., 34, L22504, doi:10.1029/ 2007GL031474.

Deser, C., G. Magnusdottir, R. Saravanan, and A. Phillips, 2004: The effects of North Atlantic SST and sea ice anomalies on the winter circulation in CCM3. Part II: Direct and indirect components of the response. J. Climate, 17, 877-889, doi:10.1175/1520-0442(2004)017<0877:TEONAS >2.0.CO;2.

— , R. A. Tomas, and S. Peng, 2007: The transient atmospheric circulation response to North Atlantic SST and sea ice anomalies. J. Climate, 20, 4751-4767, doi:10.1175/JCLI4278.1.

Dutra, E., S. Kotlarski, P. Viterbo, G. Balsamo, P. M. A. Miranda, C. Schär, P. Bissolli, and T. Jonas, 2011: Snow cover sensitivity to horizontal resolution, parameterizations, and atmospheric forcing in a land surface model. J. Geophys. Res., 116, D21109, doi:10.1029/2011JD016061.
Fasullo, J., 2004: A stratified diagnosis of the Indian monsoon-Eurasian snow cover relationship. J. Climate, 17, 1110-1122, doi:10.1175/ 1520-0442(2004)017<1110:ASDOTI >2.0.CO;2.

Fletcher, C. G., P. J. Kushner, and J. Cohen, 2007: Stratospheric control of the extratropical circulation response to surface forcing. Geophys. Res. Lett., 34, L21802, doi:10.1029/2007GL031626.

— S. C. Hardiman, P. J. Kushner, and J. Cohen, 2009: The dynamical response to snow cover perturbations in a large ensemble of atmospheric GCM integrations. J. Climate, 22, 1208-1222, doi:10.1175/2008JCLI2505.1.

Francis, J. A., W. Chan, D. J. Leathers, J. R. Miller, and D. E. Veron, 2009: Winter Northern Hemisphere weather patterns remember summer Arctic sea-ice extent. Geophys. Res. Lett., 36, L07503, doi:10.1029/2009GL037274.

Frankignoul, C., A. Czaja, and B. L'Heveder, 1998: Air-sea feedback in the North Atlantic and surface boundary conditions for ocean models. J. Climate, 11, 2310-2324, doi:10.1175/ 1520-0442(1998)011<2310:ASFITN > 2.0.CO;2.

- , N. Sennéchael, Y.-O. Kwon, and M. A. Alexander, 2011: Influence of the meridional shifts of the Kuroshio and the Oyashio Extensions on the atmospheric circulation. J. Climate, 24, 762-777, doi:10.1175/2010JCLI3731.1.

,$- \ldots$, and P. Cauchy, 2014: Observed atmospheric response to cold season sea ice variability in the Arctic. J. Climate, 27, 1243-1254, doi:10.1175/JCLI-D-13-00189.1.

Furtado, J. C., J. L. Cohen, A. H. Butler, E. E. Riddle, and A. Kumar, 2015: Eurasian snow cover variability and links to winter climate in the CMIP5 models. Climate Dyn., 45, 25912605, doi:10.1007/s00382-015-2494-4.

—_ _ _ - and E. Tziperman, 2016: The combined influences of autumnal snow and sea ice on Northern Hemisphere winters. Geophys. Res. Lett., 43, 3478-3485, doi:10.1002/ 2016GL068108.

García-Serrano, J., C. Frankignoul, G. Gastineau, and A. de la Cámara, 2015: On the predictability of the winter EuroAtlantic climate: Lagged influence of autumn Arctic sea ice. J. Climate, 28, 5195-5216, doi:10.1175/JCLI-D-14-00472.1.

__ and Coauthors, 2017: Multi-model assessment of linkages between eastern Arctic sea-ice variability and the EuroAtlantic atmospheric circulation in current climate. Climate Dyn., doi:10.1007/s00382-016-3454-3, in press.

Gastineau, G., and C. Frankignoul, 2015: Influence of the North Atlantic SST variability on the atmospheric circulation during the twentieth century. J. Climate, 28, 1396-1416, doi:10.1175/ JCLI-D-14-00424.1.

Gong, G., D. Entekhabi, J. Cohen, and D. Robinson, 2004: Sensitivity of atmospheric response to modeled snow anomaly characteristics. J. Geophys. Res., 109, D06107, doi:10.1029/ 2003JD004160.

Handorf, D., R. Jaiser, K. Dethloff, A. Rinke, and J. Cohen, 2015: Impacts of Arctic sea ice and continental snow cover changes on atmospheric winter teleconnections. Geophys. Res. Lett., 42, 2367-2377, doi:10.1002/2015GL063203.

Honda, M., J. Inoue, and S. Yamane, 2009: Influence of low Arctic sea-ice minima on anomalously cold Eurasian winters. Geophys. Res. Lett., 36, L08707, doi:10.1029/2008GL037079.

Hurrell, J. W., 1995: Decadal trends in the North Atlantic Oscillation: Regional temperatures and precipitation. Science, $\mathbf{2 6 9}$ 676-679, doi:10.1126/science.269.5224.676.

Jaiser, R., T. Nakamura, D. Handorf, K. Dethloff, J. Ukita, and K. Yamazaki, 2016: Atmospheric winter response to Arctic sea ice changes in reanalysis data and model simulations. J. Geophys. Res., 121, 7564-7577, doi:10.1002/2015JD024679. 
Jeong, J.-H., T. Ou, H. W. Linderholm, B.-M. Kim, S.-J. Kim, J.-S. Kug, and D. Chen, 2011: Recent recovery of the Siberian high intensity. J. Geophys. Res., 116, D23102, doi:10.1029/2011JD015904.

_ H. W. Linderholm, S. H. Woo, C. Folland, B. M. Kim, S. J. Kim, and D. Chen, 2013: Impacts of snow initialization on subseasonal forecasts of surface air temperature for the cold season. J. Climate, 26, 1956-1972, doi:10.1175/JCLI-D-12-00159.1.

Kaiser, H. F., 1958: The Varimax criterion for analytic rotations in factor analysis. Psychometrika, 23, 187-200, doi:10.1007/ BF02289233.

Kim, B.-M., S.-W. Son, S.-K. Min, J.-H. Jeong, S.-J. Kim, X. Zhang, T. Shim, and J.-H. Yoon, 2014: Weakening of the stratospheric polar vortex by Arctic sea-ice loss. Nat. Commun., 5, 4646, doi:10.1038/ncomms5646.

King, M. P., M. Hell, and N. Keenlyside, 2016: Investigation of the atmospheric mechanisms related to the autumn sea ice and winter circulation link in the Northern Hemisphere. Climate Dyn., 46, 1185-1195, doi:10.1007/s00382-015-2639-5.

Koenigk, T., M. Caian, G. Nikulin, and S. Schimanke, 2016: Regional Arctic sea ice variations as predictor for winter climate conditions. Climate Dyn., 46, 317-337, doi:10.1007/ s00382-015-2586-1.

Kuroda, Y., and K. Kodera, 1999: Role of planetary waves in the stratosphere-troposphere coupled variability in the Northern Hemisphere winter. Geophys. Res. Lett., 26, 2375-2378, doi:10.1029/1999GL900507.

Luo, D., Y. Xiao, Y. Yao, A. Dai, I. Simmonds, and C. L. Franzke, 2016: Impact of Ural blocking on winter warm Arctic-cold Eurasian anomalies. Part I: Blocking-induced amplification. J. Climate, 29, 3925-3947, doi:10.1175/JCLI-D-15-0611.1.

Magnusdottir, G., C. Deser, and R. Saravanan, 2004: The effects of North Atlantic SST and sea ice anomalies on the winter circulation in CCM3. Part I: Main features and storm track characteristics of the response. J. Climate, 17, 857-876, doi:10.1175/1520-0442(2004)017<0857:TEONAS >2.0.CO;2.

Martius, O., L. M. Polvani, and H. C. Davies, 2009: Blocking precursors to stratospheric sudden warming events. Geophys. Res. Lett., 36, L14806, doi:10.1029/2009GL038776.

Nakamura, T., K. Yamazaki, K. Iwamoto, M. Honda, Y. Miyoshi, Y. Ogawa, and J. Ukita, 2015: A negative phase shift of the winter $\mathrm{AO} / \mathrm{NAO}$ due to the recent Arctic sea-ice reduction in late autumn. J. Geophys. Res., 120, 3209-3227, doi:10.1002/2014JD022848. $-,-,-,-\longrightarrow,-$, Y. Tomikawa, and J. Ukita, 2016: The stratospheric pathway for Arctic impacts on midlatitude climate. Geophys. Res. Lett., 43, 3494-3501, doi:10.1002/ 2016GL068330.

Orsolini, Y. J., R. Senan, G. Balsamo, F. J. Doblas-Reyes, F. Vitart, A. Weisheimer, A. Carrasco, and R. E. Benestad, 2013: Impact of snow initialization on sub-seasonal forecasts. Climate Dyn., 41, 1969-1982, doi:10.1007/s00382-013-1782-0.

, , F. Vitart, G. Balsamo, A. Weisheimer, and F. J. DoblasReyes, 2016: Influence of the Eurasian snow on the negative North Atlantic Oscillation in subseasonal forecasts of the cold winter 2009/2010. Climate Dyn., 47, 1325-1334, doi:10.1007/ s00382-015-2903-8.

Overland, J., J. A. Francis, R. Hall, E. Hanna, S.-J. Kim, and T. Vihma, 2015: The melting Arctic and midlatitude weather patterns: Are they connected? J. Climate, 28, 7917-7932, doi:10.1175/JCLI-D-14-00822.1.

Peings, Y., and H. Douville, 2010: Influence of the Eurasian snow cover on the Indian summer monsoon variability in observed climatologies and CMIP3 simulations. Climate Dyn., 34, 643-660, doi:10.1007/s00382-009-0565-0.
,,-- R. Alkama, and B. Decharme, 2011: Snow contribution to springtime atmospheric predictability over the second half of the twentieth century. Climate Dyn., 37, 985-1004, doi:10.1007/s00382-010-0884-1.

, D. Saint-Martin, and H. Douville, 2012: A numerical sensitivity study of the influence of Siberian snow on the northern annular mode. J. Climate, 25, 592-607, doi:10.1175/JCLI-D-11-00038.1. , E. Brun, V. Mauvais, and H. Douville, 2013: How stationary is the relationship between Siberian snow and Arctic Oscillation over the 20th century? Geophys. Res. Lett., 40, 183-188, doi:10.1029/2012GL054083.

Petoukhov, V., and V. A. Semenov, 2010: A link between reduced Barents-Kara sea ice and cold winter extremes over northern continents. J. Geophys. Res., 115, D21111, doi:10.1029/ 2009JD013568.

Riddle, E. E., A. H. Butler, J. C. Furtado, J. L. Cohen, and A. Kumar, 2013: CFSv2 ensemble prediction of the wintertime Arctic Oscillation. Climate Dyn., 41, 1099-1116, doi:10.1007/ s00382-013-1850-5.

Saito, K., and J. Cohen, 2003: The potential role of snow cover in forcing interannual variability of the major Northern Hemisphere mode. Geophys. Res. Lett., 30, 1302, doi:10.1029/2002GL016341.

,$- \ldots$, and D. Entekhabi, 2001: Evolution of atmospheric response to early-season Eurasian snow cover anomalies. Mon. Wea. Rev., 129, 2746-2760, doi:10.1175/ 1520-0493(2001)129<2746:EOARTE > 2.0.CO;2.

Scaife, A. A., and Coauthors, 2014: Skillful long-range prediction of European and North American winters. Geophys. Res. Lett., 41, 2514-2519, doi:10.1002/2014GL059637.

Seviour, W. J. M., L. J. Gray, and D. M. Mitchell, 2016: Stratospheric polar vortex splits and displacements in the high-top CMIP5 climate models. J. Geophys. Res., 121, 1400-1413, doi:10.1002/2015JD024178.

Smoliak, B. V., and J. M. Wallace, 2015: On the leading patterns of Northern Hemisphere sea level pressure variability. J. Atmos. Sci., 72, 3469-3486, doi:10.1175/JAS-D-14-0371.1.

Takaya, K., and H. Nakamura, 2008: Precursory changes in planetary wave activity for midwinter surface pressure anomalies over the Arctic. J. Meteor. Soc. Japan, 86, 415-427, doi:10.2151/jmsj.86.415.

Vautard, R., 1990: Multiple weather regimes over the North Atlantic: Analysis of precursors and successors. Mon. Wea. Rev., 118, 2056-2081, doi:10.1175/1520-0493(1990)118<2056: MWROTN $>2.0 . \mathrm{CO} ; 2$.

Wegmann, M., and Coauthors, 2015: Arctic moisture source for Eurasian snow cover variations in autumn. Environ. Res. Lett., 10, 054015, doi:10.1088/1748-9326/10/5/054015.

Woollings, T., A. Charlton-Perez, S. Ineson, A. G. Marshall, and G. Masato, 2010: Associations between stratospheric variability and tropospheric blocking. J. Geophys. Res., 115, D06108, doi:10.1029/2009JD012742.

Wu, Q., and X. Zhang, 2010: Observed forcing-feedback processes between Northern Hemisphere atmospheric circulation and Arctic sea ice coverage. J. Geophys. Res., 115, D14119, doi:10.1029/2009JD013574.

Yamamoto, K., Y. Tachibana, M. Honda, and J. Ukita, 2006: Intraseasonal relationship between the Northern Hemisphere sea ice variability and the North Atlantic Oscillation. Geophys. Res. Lett., 33, L14711, doi:10.1029/2006GL026286.

Zhang, Y., T. Li, and B. Wang, 2004: Decadal change of the spring snow depth over the Tibetan Plateau: The associated circulation and influence on the East Asian summer monsoon. J. Climate, 17, 2780-2793, doi:10.1175/1520-0442(2004)017<2780: DCOTSS $>2.0 . \mathrm{CO} ; 2$. 